\title{
Analyses of the Population Structure in a Global Collection of Phytophthora nicotianae Isolates Inferred from Mitochondrial and Nuclear DNA Sequences
}

\author{
Marco A. Mammella, Frank N. Martin, Santa O. Cacciola, Michael D. Coffey, Roberto Faedda, and Leonardo Schena
}

First and sixth authors: Dipartimento di Agraria, Università degli Studi Mediterranea, Località Feo di Vito, 89122 Reggio Calabria, Italy; second author: United States Department of Agriculture-Agricultural Research Service, 1636 East Alisal Street, Salinas, CA 93905; third and fifth authors: Dipartimento di Gestione dei Sistemi Agroalimentari e Ambientali, Università degli Studi, Via Santa Sofia, 100, 95123 Catania, Italy; and fourth author: Department of Plant Pathology and Microbiology, 1129 Batchelor Hall, University of California, Riverside 92521.

Accepted for publication 25 January 2013.

\begin{abstract}
Mammella, M. A., Martin, F. N., Cacciola, S. O., Coffey, M. D., Faedda, R., and Schena, L. 2013. Analyses of the population structure in a global collection of Phytophthora nicotianae isolates inferred from mitochondrial and nuclear DNA sequences. Phytopathology 103:610-622.

Genetic variation within the heterothallic cosmopolitan plant pathogen Phytophthora nicotianae was determined in 96 isolates from a wide range of hosts and geographic locations by characterizing four mitochondrial (10\% of the genome) and three nuclear loci. In all, 52 single-nucleotide polymorphisms (SNPs) (an average of 1 every $58 \mathrm{bp}$ ) and 313 sites with gaps representing 5,450 bases enabled the identification of 50 different multilocus mitochondrial haplotypes. Similarly, 24 SNPs (an average of 1

nuclear genotypes. Both mitochondrial and nuclear markers revealed a high level of dispersal of isolates and an inconsistent geographic structuring of populations. However, a specific association was observed for host of origin and genetic grouping with both nuclear and mitochondrial sequences. In particular, the majority of citrus isolates from Italy, California, Florida, Syria, Albania, and the Philippines clustered in the same mitochondrial group and shared at least one nuclear allele. A similar association was also observed for isolates recovered from Nicotiana and Solanum spp. The present study suggests an important role of nursery populations in increasing genetic recombination within the species and the existence of extensive phenomena of migration of isolates that have been likely spread worldwide with infected plant material.
\end{abstract} every $69 \mathrm{bp}$ ), with heterozygosity observed at each locus, were observed in three nuclear regions (hyp, scp, and $\beta$-tub) differentiating 40 multilocus

The oomycete Phytophthora nicotianae Breda de Haan ( $P$. parasitica Dastur) is distributed worldwide and has a broad host range infecting herbaceous and perennial host plants, causing foliar and fruit diseases as well as root and crown rots (15). The pathogen is particularly known as the causal agent of tobacco black shank and citrus root rot and gummosis but it can cause severe damage on many other plants, including ornamental, horticultural and fruit tree species (15). In particular, P. nicotianae is a major causal agent of root rot in nurseries of ornamental plants in Mediterranean regions $(2,7,47,49)$.

Despite the economic importance of $P$. nicotianae, little is known about the structure of its population. The current state of knowledge is mainly restricted to populations from tobacco and are the results of studies of physiological aspects, such as resistance to fungicides (mainly the phenylamides mefenoxam and metalaxyl) and differential pathogenicity on tobacco cultivars $(29,50)$. In the last 10 years, several molecular investigations have been conducted to analyze intraspecific variability within $P$. nicotianae populations; however, most of them focused on isolates from a single host (tobacco) and were designed to study isolates within specific fields or from the same geographic region $(34,59$, $65)$. Furthermore, the majority of these studies have been con-

Corresponding author: L. Schena; E-mail address: 1schena@unirc.it

* The $\boldsymbol{e}$-Xtra logo stands for "electronic extra" and indicates that the online version contains two supplemental tables.

http://dx.doi.org/10.1094/PHYTO-10-12-0263-R

(c) 2013 The American Phytopathological Society
Additional keywords: intraspecific variability. ducted using the random amplified polymorphic DNA (RAPD) technique, which does not readily enable the comparison of data from different laboratories.

Other electrophoretic markers such as restriction fragment length polymorphisms, amplified fragment length polymorphisms (AFLPs), and simple-sequence repeats (SSRs) have been utilized to study the population biology of Phytophthora spp. $(12,42)$. In particular, AFLP was utilized to characterize a large number of $P$. nicotianae isolates from ornamental plants in different nurseries in Tennessee and identified six clonal lineages isolated from the same facility (36). However, such electrophoretic markers are not optimal for phylogenetic and genealogical reconstruction because comigrating bands shared by two individuals do not necessarily reflect descent from a common ancestor (27). In contrast, nucleotide sequence data offer the possibility of reconstructing patterns of descent among genotypes within a species or among populations of one or more species (24). In recent years, such approaches have been effectively utilized to study population structure, evolution, center of origin, and patterns of migration in P. infestans $(8,22,26)$, P. ramorum $(24,25)$, and P. capsici $(20$, 31,32).

Single-nucleotide polymorphisms (SNPs) have lower mutation rates $\left(10^{-8}\right.$ to $\left.10^{-9}\right)$ compared with SSRs $\left(10^{-2}\right.$ to $\left.10^{-6}\right)$ and, because multiple mutation events are improbable on the same site, most SNPs are bi-allelic and, therefore, appropriate for highthroughput genotyping of a diploid organism like $P$. nicotianae $(5,55)$. SNPs are ideal for evolutionary studies because they are widespread in the genome and several unlinked nuclear loci are required to estimate population genetic parameters with statistical 
confidence (1). Furthermore, SNPs are easier to screen compared with SSRs. Even when, as in the case of $P$. nicotianae, genomic data are not available, SNPs can be identified by comparative genomic approaches designing primers to conserved flanking regions of related species. Using this strategy, a panel of mitochondrial and nuclear SNPs were discovered for a number of Phytophthora spp. representative of the genus $(53,54)$.

In a recent study, 20 different mitochondrial haplotypes of $P$. nicotianae grouping in five clades were identified from 51 isolates mainly recovered in Italy (39) by analyzing two polymorphic intergenic regions flanked by genes $\operatorname{trn} \mathrm{Y}$ and $r n s$ and by gene $\operatorname{trn} \mathrm{W}$ and $\operatorname{cox} 2$. However, the different modes of inheritance and model of evolution in mitochondrial compared with nuclear DNA can evaluate different genetic components of variability. Some evolutionary processes can be explained only through the analyses of nuclear markers because mitochondrial DNA is uniparentally inherited and is much smaller compared with nuclear DNA (21). In particular, mitochondrial analyses conducted alone with an outcrossing species like $P$. nicotianae may produce incomplete results (64). The combined analysis of nuclear and mitochondrial genomes provides a more comprehensive insight into the evolutionary forces acting on natural populations.

In the present study, four mitochondrial and three nuclear loci containing SNPs were analyzed to investigate the structure of $P$. nicotianae populations in relation to geographic origin and hosts and to acquire information about prevalent reproduction systems and mechanisms that have facilitated its global distribution.

\section{MATERIALS AND METHODS}

Isolates of $\boldsymbol{P}$. nicotianae and DNA extraction. In total, 96 isolates of $P$. nicotianae from six continents and various hosts (mainly citrus, tobacco, and ornamental species in nurseries) were evaluated (Table 1). Of these, 51 isolates were also analyzed by Mammella et al. (39), with an additional 45 new isolates from the World Phytophthora Genetic Resources Collection at the University of California, Riverside (http://phytophthora.ucr.edu) added to the analysis. DNA from these was extracted as described by Blair et al. (3).

Selection of mitochondrial and nuclear markers. Polymorphic mitochondrial DNA regions potentially containing SNPs were identified by aligning and comparing the complete mitochondrial genome of $P$. nicotianae (F. Martin, unpublished data) with the mitochondrial genomes of P. infestans (NC_002387, AY894835, AY898627, and AY898628), P. ramorum (DQ832718), and $P$. sojae (DQ832717). Sequences were aligned using Clustal W implemented in the software Accelrys Gene (ver. 2.5; Accelrys Inc., San Diego, CA). Several potentially useful regions were manually identified and screened (amplified and sequenced) for the presence of SNPs using 15 isolates representative of five different clades identified within $P$. nicotianae in a previous study (39). Mitochondrial regions selected for in-depth analysis (trnGrns, rns-cox2, cox2+spacer, and atpl-nad5) represented $10 \%$ of the mitochondrial genome of $P$. nicotianae, had a length appropriate for polymerase chain reaction (PCR) amplification and sequencing, and were characterized by conserved flanking regions from which primers were designed (Fig. 1; Table 2). Additional internal primers were used for the sequencing of cox $2+$ spacer and atp1-nad5 regions from some isolates that did not produce clean reads with primers used for the amplification (Table 2).

Several reported nuclear genes were evaluated for the presence of SNPs using a restricted number of representative isolates of $P$. nicotianae. Selected regions represented a hypothetical conserved protein (hyp) amplified with primers I11F-I12R (53), the Scp-like protein ( $s c p$ ) amplified with primers NscpF-NscpR (35), and the $\beta$-tubulin $(\beta$-tub) gene (3). Additional primers to amplify the $\beta$ tub gene (NtubF1-NtubR1) were designed because those reported by Blair et al. (3) did not perfectly match the sequence of the gene of $P$. nicotianae (EU080504). Furthermore, nested sequencing primers (NtubF2-NtubR2) were utilized with a limited number isolates to improve the quality of sequences (Table 2).

Amplification and sequencing of target genes. Amplifications were run in a total volume of $25 \mu$ l containing $1 \mu \mathrm{l}$ of genomic DNA (approximately $10 \mathrm{ng}$ ), $1 \times$ PCR buffer, $0.1 \mathrm{mM}$ dNTPs, 1 unit of Taq polymerase (Applied Biosystems, Carlsbad, $\mathrm{CA}$ ), and $0.5 \mu \mathrm{M}$ each primer. The concentration of $\mathrm{MgCl}_{2}$ and the annealing temperature were optimized for each primer pair (Table 2). Amplification conditions were $95^{\circ} \mathrm{C}$ for $3 \mathrm{~min}$ followed by 40 cycles of $1 \mathrm{~min}$ at $95^{\circ} \mathrm{C}, 1 \mathrm{~min}$ at the annealing temperature (Table 2), and $1 \mathrm{~min}$ at $72^{\circ} \mathrm{C}$. All reactions ended with a final extension of $5 \mathrm{~min}$ at $72^{\circ} \mathrm{C}$. Amplicons were analyzed by electrophoresis in $1.5 \%$ agarose gels containing SYBR Safe DNA gel stain (Invitrogen, Carlsbad, CA) in $1 \times$ Tris-borate-EDTA buffer and visualized with UV light. PCR products were purified using ExoSap (USB, Cleveland) in accordance with manufacturer's instructions and sent to the Nucleic Acid Sequencing Facility at Penn State University (University Park, PA) for sequencing. For each nuclear region where heterozygous bases were identified, amplicons from three different isolates were selected and cloned using the TOPO easy vector kit according to manufacturer's protocol (Invitrogen). For each isolate, 10 different clones were sequenced as described above but using standard T7 and T3 primers in order to confirm the presence of heterozygosity and determine haplotypes.

Analysis of sequences. Sequence chromatograms were evaluated for reliability and utilized to generate a consensus sequence using Sequencher 4.7 (Gene Codes, Ann Arbor, MI). Unreliable sequences were reamplified and sequenced using nested primers. Consensus sequences were aligned and manually analyzed for the presence of SNPs and indels in MacClade (ver. 4.02; Sinauer Associates, Sunderland, MA). All polymorphic sites observed in the alignment were confirmed in the chromatograms. Heterozygous SNPs were identified in the nuclear coding regions by the presence of double peaks in both forward and reverse sequences and were marked with standard degeneracy codes.

Genetic diversity. Mitochondrial and nuclear genetic diversity was evaluated for each individual region and for the combined data set of sequences (Table 3). The number of polymorphic sites, haplotype or allele reconstruction, and nucleotide diversity $(\pi)$, were analyzed using DnaSP ver. 5.10.01 (38) with gaps included in the analysis. The number of multilocus haplotypes and genotypes was determined manually and using an SNP allele and position-calling program (MJBv1.2Gba) edited in python (N. Feau and G. Bilodeau, unpublished data).

Nucleotide and allele diversity were determined for the nuclear regions hyp and $\beta$-tub (Table 3 ) but not for the scp gene, because the sequencing of cloned amplicons from this latter gene for some isolates revealed more than two different alleles. For the hyp region, alleles were determined through a simple clone subtraction approach using sequences of cloned isolates (P1452, IRF5, and P7330) as known alleles. To determine alleles of the $\beta$-tub region, the software PHASE v2.1.1 with input file automatically formatted in SeqPHASE (18) was used, because this gene contained a higher number of heterozygous SNPs. The model for nonintragenic recombination was applied for the analysis. Standard search settings were 100 number of iterations, 1 thinning interval, and 100 as burn-in. Cloned and sequenced alleles from isolates P6915, P6113, and P7346 were treated as known alleles. The analysis was run five times for the same data set using a different starting seed.

The positions of synonymous and nonsynonymous substitution were inferred using a specific GenBank $P$. nicotianae sequence (EU080504) for the $\beta$-tub gene and the orthologous sequences retrieved from the $P$. infestans genome database (http://www. broadinstitute.org/annotation/genome/phytophthora_infestans) for hyp (PITG_18320.2) and scp (PITG_10036.1) genes. 
Phylogenetic analysis and population structure. Phylogenetic analyses were conducted for the combined data set of mitochondrial sequences using maximum parsimony, maximum likelihood, and Bayesian methods (Fig. 2). A partition homogeneity test (17) was performed on the concatenated data set with PAUP v4.0b10 (Sinaur Associates) to test the congruence of data using a heuristic search with 1,000 replicates. The maximum parsimony analysis was performed in PAUP using a heuristic search algorithm with random stepwise addition of taxa (10 replicates), tree bisection reconnection branch swapping, and multiple trees option. The statistical support was determined by bootstrap values for 1,000 replicates. TOPALi v2 (46) was used to determine the substitution model that best fit the data. The model $\mathrm{HKY}+\mathrm{I}+\mathrm{G}$ was selected for the Bayesian and maximum likelihood phylogenetic analysis using MrBayes version 3.1.1 (52) and
PhyML version 2.4.5 (28), respectively, implemented in TOPALi. Bayesian analysis was performed with four runs conducted simultaneously for 500,000 generations, with $10 \%$ sampling frequency and burn-in of $30 \%$. Maximum likelihood was performed with 100 bootstrap replicates.

Phylogenetic analysis was not possible for the nuclear data due to the high level of heterozygosity. However, the concatenated data set of nuclear sequences was utilized to construct a neighborjoining tree and evaluate relationships among different multilocus genotypes. The tree was constructed using absolute measure of distances and a random input order of sequences in PAUP v4.0b10.

The population structure of $P$. nicotianae was analyzed by generating networks of isolates with the statistical parsimony algorithm implemented in TCS ver. 1.21 (10). Networks were

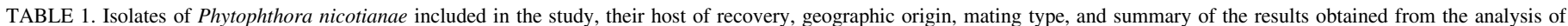
mitochondrial and nuclear DNA

\begin{tabular}{|c|c|c|c|c|c|c|c|c|c|c|c|c|c|c|c|c|}
\hline \multirow[b]{3}{*}{ Isolates $^{\mathrm{a}}$} & \multirow[b]{3}{*}{ Host } & \multirow[b]{3}{*}{ Origin } & \multirow[b]{3}{*}{$\mathrm{MT}^{\mathrm{b}}$} & \multicolumn{8}{|c|}{ Mitochondrial DNA ${ }^{\mathrm{c}}$} & \multirow[b]{3}{*}{$\mathrm{MMH}^{\mathrm{d}}$} & \multirow{2}{*}{\multicolumn{3}{|c|}{ Nuclear DNA ${ }^{\mathrm{e}}$}} & \multirow[b]{3}{*}{$\mathrm{MNG}^{\mathrm{f}}$} \\
\hline & & & & \multicolumn{2}{|c|}{ trnG-rns } & \multicolumn{2}{|c|}{$r n s-\operatorname{cox} 2$} & \multicolumn{2}{|c|}{ cox $2+$ spacer } & \multicolumn{2}{|c|}{ atp1-nad5 } & & & & & \\
\hline & & & & MH & Size & MH & Size & MH & Size & MH & Size & & Hyp & $S c p$ & $\beta-t u b$ & \\
\hline Albicocco $9 *$ & Prunus armeniaca & Southern Italy & $\mathrm{A} 2$ & h1 & 606 & h1 & 577 & h1 & 910 & h1 & 876 & $\mathrm{H} 1$ & $\mathrm{~g} 1(\mathrm{a} 1)$ & g1 & $\mathrm{g} 1$ (a1/a2) & G1 \\
\hline P7449 & Chrysanthemum sp. & India & $\mathrm{A} 1$ & $\mathrm{~h} 2$ & 608 & h2 & 577 & h2 & 910 & $\mathrm{~h} 2$ & 788 & $\mathrm{H} 2$ & $\mathrm{~g} 2$ (a1/a3) & g2 & g2 (a1) & G2 \\
\hline P1495 & Nicotiana tabacum & Australia & $\mathrm{A} 2$ & h3 & 607 & h2 & 577 & h2 & 910 & h3 & 788 & $\mathrm{H} 3$ & g1 (a1) & g3 & g3 (a4) & G3 \\
\hline P1955 & N. tabacum & South Africa & $\mathrm{A} 1$ & $\mathrm{~h} 2$ & 608 & h2 & 577 & h2 & 910 & h3 & 788 & $\mathrm{H} 4$ & g1 (a1) & $\mathrm{g} 2$ & g4 (a4/a5) & G4 \\
\hline P6115 & Gypsophila sp. & Japan & $\mathrm{A} 2$ & $\mathrm{~h} 2$ & 608 & $\mathrm{~h} 2$ & 577 & $\mathrm{~h} 2$ & 910 & h3 & 788 & $\mathrm{H} 4$ & g1 (a1) & g3 & g5 (a2/a4) & G5 \\
\hline Ciclamino1* & Cyclamen sp. & Southern Italy & $\mathrm{A} 1$ & $\mathrm{~h} 4$ & 608 & h2 & 577 & h2 & 910 & $\mathrm{~h} 2$ & 788 & H5 & g1 (a1) & g4 & g6 (a2/a3) & G6 \\
\hline Correa5* & Correa reflexa & Southern Italy & $\mathrm{A} 1$ & h5 & 607 & h1 & 577 & $\mathrm{~h} 2$ & 910 & $\mathrm{~h} 4$ & 785 & H6 & g1 (a1) & $\mathrm{g} 1$ & g7 (a1/a3) & G7 \\
\hline Correa8* & C. reflexa & Southern Italy & $\mathrm{A} 1$ & h6 & 608 & h1 & 577 & h2 & 910 & h5 & 785 & $\mathrm{H} 7$ & g1 (a1) & g1 & g7 (a1/a3) & G7 \\
\hline Correa3* & C. reflexa & Southern Italy & $\mathrm{A} 1$ & h6 & 608 & h1 & 577 & h2 & 910 & h5 & 785 & $\mathrm{H} 7$ & g1 (a1) & $\mathrm{g} 1$ & g7 (a1/a3) & G7 \\
\hline Dodonea $\operatorname{Rad} 1 *$ & Dodonaea viscosa & Southern Italy & $\mathrm{A} 2$ & $\mathrm{~h} 7$ & 605 & h1 & 577 & h2 & 910 & h1 & 876 & $\mathrm{H} 8$ & g1 (a1) & g1 & $\mathrm{g} 1(\mathrm{a} 1 / \mathrm{a} 2)$ & G1 \\
\hline Dodonea Col1* & D. viscosa & Southern Italy & $\mathrm{A} 2$ & $\mathrm{~h} 7$ & 605 & h1 & 577 & h2 & 910 & h1 & 876 & $\mathrm{H} 8$ & g1 (a1) & $\mathrm{g} 1$ & $\mathrm{~g} 1(\mathrm{a} 1 / \mathrm{a} 2)$ & G1 \\
\hline IMI 268688 & Citrus sp. & Trinidad & A1 & $\mathrm{h} 8$ & 607 & h1 & 577 & h3 & 910 & h6 & 876 & $\mathrm{H} 9$ & g1 (a1) & g5 & g8 (a4/a6) & G8 \\
\hline P6915 & Dieffenbachia maculata & Germany & $\mathrm{A} 2$ & h9 & 607 & h3 & 464 & h4 & 910 & h7 & 882 & $\mathrm{H} 10$ & g1 (a1) & $\mathrm{g} 1$ & g9 (a4/a7) & G9 \\
\hline P10297 & D. maculata & Florida & A2 & h9 & 607 & h3 & 464 & h4 & 910 & $\mathrm{~h} 7$ & 882 & H10 & g1 (a1) & g1 & g9 (a4/a7) & G9 \\
\hline P1492 & N. tabacum & Australia & $\mathrm{A} 2$ & h10 & 619 & h1 & 577 & h5 & 910 & $\mathrm{~h} 8$ & 890 & H11 & $\mathrm{g} 3(\mathrm{a} 1 / \mathrm{a} 2)$ & $\mathrm{g} 1$ & g7 (a1/a3) & G10 \\
\hline P1751 & N. tabacum & Australia & A1 & h10 & 619 & h1 & 577 & h5 & 910 & h8 & 890 & H11 & g3 (a1/a2) & $\mathrm{g} 1$ & $\mathrm{~g} 10(\mathrm{a} 3)$ & G11 \\
\hline P1752 & N. tabacum & Australia & A1 & h10 & 619 & h1 & 577 & h5 & 910 & $\mathrm{~h} 8$ & 890 & H11 & g3 (a1/a2) & g1 & g7 (a1/a3) & G10 \\
\hline P1753 & N. tabacum & Australia & A1 & h10 & 619 & h1 & 577 & h5 & 910 & $\mathrm{~h} 8$ & 890 & H11 & g3 (a1/a2) & g1 & g7 (a1/a3) & G10 \\
\hline P7387 & Hippeastrum sp. & Netherlands & $\mathrm{A} 2$ & h10 & 619 & h1 & 577 & h5 & 910 & $\mathrm{~h} 8$ & 890 & H11 & $\mathrm{g} 2$ (a1/a3) & g1 & g11 (a1/a5) & G12 \\
\hline P7330 & Lavandula sp. & Australia & $\mathrm{A} 2$ & h10 & 619 & h1 & 577 & h5 & 910 & $\mathrm{~h} 8$ & 890 & H11 & g3 (a1/a2) & $\mathrm{g} 1$ & g7 (a1/a3) & G10 \\
\hline P7665 & Leucodendron sp. & Australia & $\mathrm{A} 1$ & h10 & 619 & h1 & 577 & h5 & 910 & $\mathrm{~h} 8$ & 890 & H11 & g3 (a1/a2) & $\mathrm{g} 1$ & g7 (a1/a3) & G10 \\
\hline STA24* & Rhamnus alaternus & Southern Italy & $\mathrm{A} 2$ & h10 & 619 & h1 & 577 & h5 & 910 & $\mathrm{~h} 8$ & 890 & H11 & $\mathrm{g} 2(\mathrm{a} 1 / \mathrm{a} 3)$ & g1 & $\mathrm{g} 11(\mathrm{a} 1 / \mathrm{a} 5)$ & G12 \\
\hline P6113 & Lilium sp. & Japan & $\mathrm{A} 2$ & h11 & 619 & h4 & 577 & h5 & 910 & h9 & 898 & H12 & g1 (a1) & g4 & g5 (a2/a4) & G13 \\
\hline P3813 & Catharanthus sp. & California & A1 & h10 & 619 & h1 & 577 & h5 & 910 & h10 & 890 & H13 & $\mathrm{g} 3$ (a1/a2) & g1 & $\mathrm{g} 2(\mathrm{a} 1)$ & G14 \\
\hline P16824 & Catharanthus roseus & Japan & A1 & h10 & 619 & h1 & 577 & h5 & 910 & h10 & 890 & H13 & g3 (a1/a2) & g1 & g10 (a3) & G11 \\
\hline P3458 & Carthamus tinctorius & Venezuela & A1 & h12 & 620 & h1 & 577 & h6 & 910 & h11 & 890 & H14 & g4 (a2) & g6 & g2 (a1) & G15 \\
\hline Ceanothus* & Ceanothus sp. & Southern Italy & A2 & h13 & 619 & h5 & 577 & h7 & 910 & h12 & 891 & H15 & g1 (a1) & g7 & g7 (a1/a3) & G16 \\
\hline KVB* & Howea sp. & Southern Italy & $\mathrm{A} 2$ & h13 & 619 & h5 & 577 & h7 & 910 & h12 & 891 & H15 & g1 (a1) & g7 & g7 (a1/a3) & G16 \\
\hline IRF $26 / 2 *$ & Impatiens sp. & Northern Italy & $\mathrm{A} 2$ & h13 & 619 & h5 & 577 & h7 & 910 & h12 & 891 & H15 & g1 (a1) & g7 & g7 (a1/a3) & G16 \\
\hline $\mathrm{Ph} 440 / 00 *$ & Cyclamen sp. & Northern Italy & $\mathrm{A} 2$ & h13 & 619 & h5 & 577 & h7 & 910 & h12 & 891 & H15 & g1 (a1) & g7 & g7 (a1/a3) & G16 \\
\hline Ph168 & Citrus sp. & Tunisia & $\mathrm{A} 1$ & h13 & 619 & h1 & 577 & h8 & 910 & h13 & 894 & H16 & g1 (a1) & $\mathrm{g} 4$ & g3 (a4) & G17 \\
\hline P0582 & N. tabacum & Kentucky & A2 & h14 & 617 & h1 & 577 & h8 & 910 & h14 & 894 & H17 & g5 (a3) & g1 & g3 (a4) & G18 \\
\hline P1335 & N. tabacum & Virginia & $\mathrm{A} 2$ & h14 & 617 & h1 & 577 & h8 & 910 & h14 & 894 & H17 & g5 (a3) & $\mathrm{g} 1$ & g3 (a4) & G18 \\
\hline P1334 & N. tabacum & Virginia & $\mathrm{A} 2$ & h14 & 617 & h1 & 577 & h8 & 910 & h14 & 894 & H17 & g5 (a3) & $\mathrm{g} 1$ & g3 (a4) & G18 \\
\hline P1333 & N. tabacum & Virginia & $\mathrm{A} 2$ & h14 & 617 & h1 & 577 & h8 & 910 & h14 & 894 & H17 & g5 (a3) & $\mathrm{g} 1$ & g3 (a4) & G18 \\
\hline P7522 & Catharanthus roseus & California & A2 & h15 & 607 & h6 & 577 & h9 & 910 & h15 & 893 & H18 & g3 (a1/a2) & g4 & g7 (a1/a3) & G19 \\
\hline P1452 & Citrus sp. & California & A1 & h16 & 607 & h6 & 577 & h9 & 910 & h16 & 892 & H19 & $\mathrm{g} 2(\mathrm{a} 1 / \mathrm{a} 3)$ & g4 & g7 (a1/a3) & G20 \\
\hline P7561 & Citrus jambiri & Philippines & A1 & h16 & 608 & h6 & 577 & h9 & 910 & h17 & 891 & $\mathrm{H} 20$ & g5 (a3) & g4 & g7 (a1/a3) & G21 \\
\hline P1569 & Citrus sp. & California & $\mathrm{A} 1$ & h16 & 607 & h6 & 577 & h9 & 910 & h18 & 893 & $\mathrm{H} 21$ & $\mathrm{~g} 2(\mathrm{a} 1 / \mathrm{a} 3)$ & $\mathrm{g} 4$ & g7 (a1/a3) & G20 \\
\hline $\mathrm{Ph} 195$ & Citrus sp. & Syria & $\mathrm{A} 1$ & h16 & 607 & h6 & 577 & h9 & 910 & h18 & 893 & $\mathrm{H} 21$ & g5 (a3) & g4 & g7 (a1/a3) & G21 \\
\hline $\mathrm{Ph} 3$ & C. clementina & Italy & $\mathrm{A} 1$ & h16 & 607 & h6 & 577 & h9 & 910 & h18 & 893 & $\mathrm{H} 21$ & g5 (a3) & g4 & g7 (a1/a3) & G21 \\
\hline P1325 & Citrus sp. & California & $\mathrm{A} 2$ & h17 & 608 & h6 & 577 & h9 & 910 & h16 & 892 & $\mathrm{H} 22$ & $\mathrm{~g} 2(\mathrm{a} 1 / \mathrm{a} 3)$ & g4 & g7 (a1/a3) & G20 \\
\hline Ferrara R11 & C. aurantium & Southern Italy & $\mathrm{A} 1$ & h16 & 607 & h6 & 577 & h9 & 910 & h19 & 893 & $\mathrm{H} 23$ & g5 (a3) & g4 & g7 (a1/a3) & G21 \\
\hline & & & & & & & & & & & & & & & inued on $n$ & tpage) \\
\hline
\end{tabular}

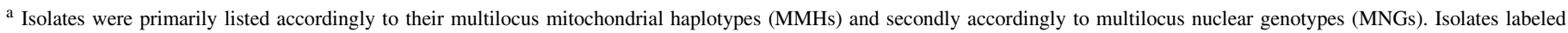
with an asterisk $(*)$ were sourced from potted ornamental species in nursery.

${ }^{\mathrm{b}} \mathrm{MT}=$ mating type.

${ }^{\mathrm{c}} \mathrm{MH}=$ mitochondrial haplotype, and Size $=$ length of the amplified fragments in base pairs.

${ }^{\mathrm{d}}$ MMHs determined for the combined mitochondrial data set of sequences (trnG-rns, rns-cox2, cox $2+$ spacer, and atp1-nad5).

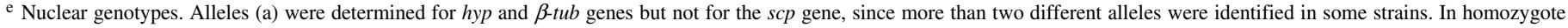
strains a single allele is indicated;

${ }^{\mathrm{f}}$ MNGs for the combined data set of sequences for the three nuclear regions (hyp, scp, and $\beta$-tub). n.d. $=$ not determined 
generated for individual mitochondrial (trnG-rns, rns-cox2, cox $2+$ spacer, and atpl-nad5) and nuclear (hyp and $\beta$-tub) regions as well as for the combined data set of mitochondrial sequences.

To determine the presence of significant genetic structuring among geographic origin (Africa, America, Asia, Australia, and Europe) and among originating host genus, combined mitochondrial haplotypes and nuclear alleles from $\beta$-tub and hyp genes where analyzed by analysis of molecular variance (AMOVA) using Arlequin 3.1 software (16). Furthermore, the Wright's inbreeding coefficients $\left(\mathrm{F}_{\mathrm{IS}}\right)(62)$ were calculated using nuclear alleles to analyze the mating system within populations from three field crops (Citrus, Nicotiana, and Solanum spp.) and from potted ornamental species in nursery (Table 1). Isolates from Solanum spp. were not included in the analysis with the hyp gene because all alleles where identical.

\section{RESULTS}

Amplification and sequencing. Four mitochondrial (trnG-rns, rns-cox2, cox2+spacer, and atp1-nad5) and three nuclear (hyp, $s c p$, and $\beta$-tub) regions were selected because they contained intraspecific variation and their amplification and sequencing was possible from the complete panel of 96 isolates (Table 1). A single exception was represented by the $\beta$-tub region of isolate P7622 because it was not possible to obtain a high-quality sequence. DNA sequences were deposited in GenBank with the following accession numbers: JF706726-JF706821 (atp1-nad5), JF706822-JF706917 (trnG-rns), JF706918-JF707013 (rns-cox2), JF707014-JF707109 (cox2+spacer), JF707110-JF707204 ( $\beta$-tub), JF707205-JF707300 (scp), and JF707301-JF707396 (hyp). Sequence alignments from both combined mitochondrial and

TABLE 1. (continued from preceding page)

\begin{tabular}{|c|c|c|c|c|c|c|c|c|c|c|c|c|c|c|c|c|}
\hline \multirow[b]{3}{*}{ Isolates $^{\mathrm{a}}$} & \multirow[b]{3}{*}{ Host } & \multirow[b]{3}{*}{ Origin } & \multirow[b]{3}{*}{$\mathrm{MT}^{\mathrm{b}}$} & \multicolumn{9}{|c|}{ Mitochondrial DNA ${ }^{\mathrm{c}}$} & & & & \multirow[b]{3}{*}{$\mathrm{MNG}^{\mathrm{f}}$} \\
\hline & & & & \multicolumn{2}{|c|}{ trnG-rns } & \multicolumn{2}{|c|}{$r n s-\operatorname{cox} 2$} & \multicolumn{2}{|c|}{$\operatorname{cox} 2+$ spacer } & \multicolumn{2}{|c|}{ atp1-nad5 } & \multirow[b]{2}{*}{$\mathrm{MMH}^{\mathrm{d}}$} & \multicolumn{3}{|c|}{ Nuclear DNA ${ }^{\mathrm{e}}$} & \\
\hline & & & & MH & Size & MH & Size & MH & Size & MH & Size & & Hyp & $S c p$ & $\beta-t u b$ & \\
\hline Ferrara R3 & C. aurantium & Southern Italy & A1 & h16 & 607 & h6 & 577 & h9 & 910 & h19 & 893 & $\mathrm{H} 23$ & g5 (a3) & $\mathrm{g} 4$ & g7 (a1/a3) & G21 \\
\hline Ferrara R8 & C. aurantium & Southern Italy & A1 & h16 & 607 & h6 & 577 & h9 & 910 & h19 & 893 & $\mathrm{H} 23$ & g5 (a3) & g4 & g7 (a1/a3) & $\mathrm{G} 21$ \\
\hline Serravalle1 & C. aurantium & Southern Italy & A1 & h16 & 607 & h6 & 577 & h9 & 910 & h19 & 893 & $\mathrm{H} 23$ & g5 (a3) & g4 & g7 (a1/a3) & G21 \\
\hline Ph87 & C. aurantium & Southern Italy & A1 & h16 & 607 & h6 & 577 & h9 & 910 & h19 & 893 & $\mathrm{H} 23$ & g5 (a3) & g4 & g7 (a1/a3) & G21 \\
\hline $\mathrm{Ph} 342 / 03 *$ & Limonium sinensis & Northern Italy & $\mathrm{A} 2$ & h16 & 607 & h6 & 577 & h9 & 910 & h19 & 893 & $\mathrm{H} 23$ & g5 (a3) & g2 & g7 (a1/a3) & G22 \\
\hline $\mathrm{Ph} 142$ & Poncirus trifoliata & Albania & A1 & h17 & 608 & h6 & 577 & h9 & 910 & h19 & 893 & $\mathrm{H} 24$ & g5 (a3) & $\mathrm{g} 4$ & g7 (a1/a3) & G21 \\
\hline Ph9 & Citrus sp. & Southern Italy & $\mathrm{A} 1$ & h17 & 608 & h6 & 577 & h9 & 910 & h19 & 893 & $\mathrm{H} 24$ & g5 (a3) & g4 & g7 (a1/a3) & G21 \\
\hline Pn17 & Citrus sp. & Florida & n.d. & h18 & 609 & h6 & 577 & h9 & 910 & h19 & 893 & $\mathrm{H} 25$ & g5 (a3) & $\mathrm{g} 1$ & g7 (a1/a3) & G23 \\
\hline Serravalle3 & Citrus sp. & Southern Italy & $\mathrm{A} 1$ & h19 & 606 & h6 & 577 & h9 & 910 & h19 & 893 & $\mathrm{H} 26$ & g5 (a3) & g4 & g7 (a1/a3) & G21 \\
\hline C 88 & Simmondsia chinensis & Southern Italy & n.d. & h20 & 609 & h7 & 577 & h9 & 910 & h20 & 881 & $\mathrm{H} 27$ & g1 (a1) & $\mathrm{g} 2$ & g12 (a1/a4) & G24 \\
\hline Nic8Vasi* & Lavandula angustifolia & Southern Italy & $\mathrm{A} 2$ & h20 & 609 & h7 & 577 & h9 & 910 & h20 & 881 & $\mathrm{H} 27$ & g1 (a1) & g2 & g12 (a1/a4) & G24 \\
\hline TL8VP* & L. angustifolia & Southern Italy & $\mathrm{A} 2$ & h20 & 609 & h7 & 577 & h9 & 910 & h20 & 881 & $\mathrm{H} 27$ & g1 (a1) & g2 & g12 (a1/a4) & $\mathrm{G} 24$ \\
\hline P1350 & N. tabacum & North Carolina & $\mathrm{A} 1$ & $\mathrm{~h} 20$ & 609 & h7 & 577 & h9 & 910 & h21 & 880 & $\mathrm{H} 28$ & g5 (a3) & $\mathrm{g} 1$ & g3 (a4) & G18 \\
\hline P0583 & N. tabacum & Kentucky & $\mathrm{A} 2$ & $\mathrm{~h} 21$ & 608 & h7 & 577 & h10 & 876 & $\mathrm{~h} 21$ & 880 & $\mathrm{H} 29$ & g6 (a2/a3) & $\mathrm{g} 1$ & g12 (a1/a4) & G25 \\
\hline P6832 & Cyclamen sp. & Greece & $\mathrm{A} 2$ & $\mathrm{~h} 20$ & 609 & h7 & 577 & $\mathrm{~h} 9$ & 910 & h22 & 881 & H30 & g1 (a1) & g4 & g3 (a4) & G17 \\
\hline P3461 & Solanum lycopersicum & UK & $\mathrm{A} 2$ & h9 & 607 & h7 & 577 & h9 & 910 & $\mathrm{~h} 20$ & 881 & H31 & g1 (a1) & $\mathrm{g} 2$ & g3 (a4) & G26 \\
\hline P3118 & S. lycopersicum & Australia & $\mathrm{A} 2$ & h9 & 607 & h7 & 577 & h9 & 910 & h20 & 881 & H31 & g1 (a1) & $\mathrm{g} 2$ & g3 (a4) & G26 \\
\hline $\mathrm{Ph} 5$ & Citrus sp. & Southern Italy & A1 & h9 & 607 & h7 & 577 & h9 & 910 & h20 & 881 & H31 & g1 (a1) & g8 & $\mathrm{g} 10(\mathrm{a} 3)$ & G27 \\
\hline $\mathrm{Ph} 653 / 03 *$ & Choisya ternata & Northern Italy & $\mathrm{A} 2$ & h9 & 607 & h7 & 577 & h9 & 910 & h20 & 881 & H31 & g1 (a1) & $\mathrm{g} 2$ & g3 (a4) & G26 \\
\hline $\mathrm{Ph} 647 \mathrm{~b} / 03 *$ & Phormium tenax & Northern Italy & $\mathrm{A} 2$ & h9 & 607 & h7 & 577 & h9 & 910 & h20 & 881 & H31 & g1 (a1) & g4 & $\mathrm{g} 12(\mathrm{a} 1 / \mathrm{a} 4)$ & G28 \\
\hline IMI 379626 & S. lycopersicum & Chile & A1 & h9 & 607 & h7 & 577 & h9 & 910 & h20 & 881 & H31 & g1 (a1) & g2 & g3 (a4) & G26 \\
\hline Melanzana1 & S. melongena & Southern Italy & A2 & h9 & 607 & h7 & 577 & h9 & 910 & h20 & 881 & H31 & g1 (a1) & g2 & g3 (a4) & G26 \\
\hline IRF5* & Polygala myrtifolia & Northern Italy & A2 & $\mathrm{h} 22$ & 609 & h7 & 577 & h9 & 910 & h22 & 881 & H32 & g7 (a1/a4) & g9 & g12 (a1/a4) & G29 \\
\hline Lavanda $1 *$ & L. angustifolia & Southern Italy & A2 & $\mathrm{h} 21$ & 608 & h7 & 577 & h9 & 910 & h20 & 881 & H33 & g1 (a1) & $\mathrm{g} 4$ & g12 (a1/a4) & G28 \\
\hline Mirtus3* & Myrtus communis & Southern Italy & A1 & $\mathrm{h} 21$ & 609 & h7 & 577 & h9 & 910 & h20 & 881 & H33 & g1 (a1) & $\mathrm{g} 4$ & g7 (a1/a3) & G30 \\
\hline Lavanda4* & L. angustifolia & Southern Italy & $\mathrm{A} 2$ & $\mathrm{~h} 23$ & 606 & h7 & 577 & h9 & 910 & h20 & 881 & H34 & g1 (a1) & g4 & $\mathrm{g} 12(\mathrm{a} 1 / \mathrm{a} 4)$ & G28 \\
\hline SCRP462 & Fragaria $\times$ ananassa & India & A1 & h9 & 607 & h8 & 570 & h9 & 910 & h23 & 895 & H35 & g1 (a1) & $\mathrm{g} 2$ & g3 (a4) & G26 \\
\hline Anthurium* & Anthurium sp. & Southern Italy & A1 & h24 & 608 & h9 & 526 & h9 & 910 & h24 & 893 & H36 & g1 (a1) & g3 & $\mathrm{g} 12(\mathrm{a} 1 / \mathrm{a} 4)$ & G31 \\
\hline Pandorea $2 C^{*}$ & Pandorea jasminoides & Southern Italy & $\mathrm{A} 2$ & h24 & 608 & h9 & 526 & h9 & 910 & h24 & 893 & H36 & g1 (a1) & g3 & g12 (a1/a4) & G31 \\
\hline $\mathrm{C} 301 *$ & Myrtus communis & Southern Italy & $\mathrm{A} 2$ & h25 & 606 & h9 & 526 & h9 & 910 & h24 & 893 & H37 & g1 (a1) & g2 & g3 (a4) & G26 \\
\hline P3815 & Rosa hybrida & United States & A2 & $\mathrm{h} 25$ & 606 & h9 & 526 & h9 & 910 & h24 & 893 & H37 & $\mathrm{g} 2$ (a1/a3) & $\mathrm{g} 10$ & g7 (a1/a3) & G32 \\
\hline Peperone GJ & Capsicum annum & Southern Italy & $\mathrm{A} 1$ & h26 & 607 & h9 & 526 & h9 & 910 & h24 & 893 & $\mathrm{H} 38$ & g1 (a1) & g6 & g4 (a4/a5) & G33 \\
\hline Peperone RC & C. annum & Southern Italy & $\mathrm{A} 2$ & h26 & 607 & h9 & 526 & h9 & 910 & h24 & 893 & H38 & g1 (a1) & g4 & g4 (a4/a5) & G34 \\
\hline Pomodoro & S. lycopersicum & Southern Italy & n.d. & h26 & 607 & h9 & 526 & h9 & 910 & h24 & 893 & H38 & g1 (a1) & g2 & g11 (a1/a5) & G35 \\
\hline P7622 & Gypsophila sp. & South Africa & A1 & h26 & 607 & h9 & 526 & h9 & 910 & h24 & 893 & H38 & g1 (a1) & g2 & n.d. & n.d. \\
\hline IRF27* & Agapanthus sp. & Northern Italy & $\mathrm{A} 2$ & h26 & 607 & h9 & 526 & h9 & 910 & h24 & 893 & H38 & g1 (a1) & g2 & g11 (a1/a5) & G35 \\
\hline IRF8* & Anemone americana & Northern Italy & A2 & h26 & 607 & h9 & 526 & h9 & 910 & h24 & 893 & $\mathrm{H} 38$ & g1 (a1) & g2 & $\mathrm{g} 11(\mathrm{a} 1 / \mathrm{a} 5)$ & G35 \\
\hline P16870 & S. lycopersicum & Spain & $\mathrm{A} 2$ & $\mathrm{~h} 26$ & 607 & h9 & 526 & h9 & 910 & h24 & 893 & H38 & g1 (a1) & g6 & g4 (a4/a5) & G32 \\
\hline P16883 & S. lycopersicum & Spain & A2 & $\mathrm{h} 26$ & 607 & h9 & 526 & h9 & 910 & h24 & 893 & H38 & g1 (a1) & g4 & g13 (a3/a5) & G36 \\
\hline P1083 & Gypsophila sp. & California & A1 & h26 & 607 & h9 & 526 & h9 & 910 & h25 & 893 & H39 & g1 (a1) & g8 & g2 (a1) & G37 \\
\hline P16823 & Karankoe sp. & Japan & $\mathrm{A} 2$ & $\mathrm{~h} 27$ & 609 & h9 & 526 & h9 & 910 & h24 & 893 & $\mathrm{H} 40$ & g1 (a1) & g4 & $\mathrm{g} 14(\mathrm{a} 3 / \mathrm{a} 4)$ & G38 \\
\hline Hybiscus B* & Hibiscus sp. & Southern Italy & $\mathrm{A} 2$ & h24 & 608 & h9 & 526 & h11 & 910 & h26 & 892 & $\mathrm{H} 41$ & g1 (a1) & g7 & g7 (a1/a3) & G16 \\
\hline MirtoP5* & Myrtus communis & Southern Italy & A2 & h26 & 607 & h9 & 526 & h9 & 910 & h27 & 893 & $\mathrm{H} 42$ & g1 (a1) & $\mathrm{g} 4$ & g12 (a1/a4) & G28 \\
\hline Pittosporo* & Pittosporum sp. & Southern Italy & A1 & h26 & 607 & h9 & 526 & h9 & 910 & h27 & 893 & $\mathrm{H} 42$ & g1 (a1) & g4 & $\mathrm{g} 2$ (a1) & G39 \\
\hline IRF3* & Polygala myrtifolia & Northern Italy & $\mathrm{A} 2$ & $\mathrm{~h} 26$ & 607 & h7 & 577 & h12 & 910 & h28 & 893 & $\mathrm{H} 43$ & g1 (a1) & $\mathrm{g} 4$ & g5 (a2/a4) & G13 \\
\hline P3456 & Hibiscus sp. & Pakistan & $\mathrm{A} 2$ & $\mathrm{~h} 28$ & 607 & h7 & 577 & h9 & 910 & h28 & 893 & $\mathrm{H} 44$ & g1 (a1) & g1 & g10 (a3) & G40 \\
\hline P3549 & Aphelandra sp. & Florida & A2 & $\mathrm{h} 25$ & 606 & h7 & 577 & h9 & 910 & h29 & 893 & $\mathrm{H} 45$ & g1 (a1) & g1 & g7 (a1/a3) & G7 \\
\hline P3234 & Hibiscus sp. & China & A2 & h26 & 607 & h7 & 577 & h9 & 910 & h28 & 893 & $\mathrm{H} 46$ & g1 (a1) & g1 & g10 (a3) & G40 \\
\hline P1577 & Citrus sp. & California & A1 & h24 & 608 & h6 & 577 & h13 & 912 & h30 & 894 & $\mathrm{H} 47$ & g1 (a1) & $\mathrm{g} 4$ & g3 (a4) & G17 \\
\hline P0700 & S. lycopersicum & Ponape & $\mathrm{A} 2$ & h24 & 607 & h7 & 577 & $\mathrm{~h} 9$ & 910 & h31 & 893 & $\mathrm{H} 48$ & g1 (a1) & $\mathrm{g} 1$ & g10 (a3) & G40 \\
\hline P7346 & Choisya ternata & United Kingdom & A1 & h26 & 607 & h9 & 526 & h9 & 910 & h28 & 893 & H49 & g1 (a1) & g2 & $\mathrm{g} 11(\mathrm{a} 1 / \mathrm{a} 5)$ & G35 \\
\hline IMI 207770 & Durio zibethinus & Malaysia & A1 & $\mathrm{h} 26$ & 607 & h7 & 577 & h9 & 910 & $\mathrm{~h} 31$ & 893 & H50 & g1 (a1) & g1 & g10 (a3) & G40 \\
\hline P10802 & Dianthus caryophyllus & Japan & A2 & $\mathrm{h} 26$ & 607 & h7 & 577 & h9 & 910 & h31 & 893 & $\mathrm{H} 50$ & g1 (a1) & $\mathrm{g} 1$ & $\mathrm{~g} 10(\mathrm{a} 3)$ & G40 \\
\hline
\end{tabular}


nuclear sequences have been deposited in TreeBASE (submission ID 12393).

Three other mitochondrial regions (secY, rps10, and rpl5) (43) (F. Martin, unpublished) and two nuclear genes (elicitin [33] and ras-related protein $Y p t 1$ ) [9]) were investigated and discarded during preliminary screenings because they did not exhibit enough variation within a representative panel of 15 isolates. Furthermore, another potentially interesting target, the necrosis-inducing protein Ppl gene (51), was discarded because it did not yield reliable sequences from all isolates.

Analysis of genetic diversity. Mitochondrial DNA. The analyses of mitochondrial regions revealed the presence of intraspecific polymorphisms in the four loci sequenced (Tables 1 and 3 ). The $r n s$-cox 2 region (length variable from 464 to $577 \mathrm{bp}$ ) was the least variable region, with $\pi$ of 0.0018 (Table 3 ). The analyzed region consisted of the entire intergenic region and portions of the flanking coding regions of the rns and cox 2 genes (39 and $58 \mathrm{bp}$, respectively) (Fig. 1). No variation was observed in these coding regions and in the trn $W$ (cca) tRNA that is within the intergenic region.

The cox $2+$ spacer region had a length between 876 and 912 bp (Table 1) and $\pi$ of 0.0022 . This region consisted of almost the entire reading frame for the $\operatorname{cox} 2$ gene (92 bases at the $5^{\prime}$ end were not included), two intergenic spacers (197 bp) flanking the putative $\operatorname{orf32}$, and a small portion (31 bp) of the coxl gene (Fig. 1). In the coding region of the $\operatorname{cox} 2$ gene, eight SNPs were identified (position 64, 114, 133, 206, 226, 547, 634, and 680) and six of them led to a nonsynonymous change in the protein sequence (Supplemental Table 1). In particular, two nonsynonymous mutations in nucleotide position 64 (Val to Leu) and 547 (Glu to Lys) differentiated two isolates (P10297 and P6915) isolated from Dieffenbachia maculata in Florida and Germany from all other isolates (Table 1).

The trnG-rns intergenic region (length of 605 to $620 \mathrm{bp}$ ) contained 12 SNPs and 33 sites with gaps giving $\pi$ of 0.0051 (Table 3 ); no variation was present in the $\operatorname{trn} G$ and $\operatorname{trn} Y$ genes flanking the intergenic region. The atpl-nad5 intergenic region (length of $785-895 \mathrm{bp}$ ) was the most variable region examined, with $\pi$ of 0.0077 as a result of 23 SNPs and 124 sites with gaps (Table 3). No variation was present in coding portions of this gene (Fig. 1). On the whole, 52 SNPs (average of 1 SNP every $59 \mathrm{bp}$ ) and 313 sites with gaps representing 5,450 bases were observed in the combined dataset for the four mitochondrial regions (Table 3 ).

Nuclear DNA. Intraspecific variability was detected in the three nuclear regions analyzed (Tables 1 and 3). In all, 3, 10, and 11 SNPs differentiated 7, 10, and 14 genotypes in the hyp, scp, and $\beta$-tub nuclear loci, respectively. In the combined data set of nuclear sequences (1,654 bp), 24 SNPs were identified (average of 1 SNP every $69 \mathrm{bp}$ ) and heterozygosity was observed at each SNP locus (Table 4). In total, 40 genotypes were observed for the combined nuclear data set and 21 of them were unique (Table 4).

A high level of nucleotide and allele diversity was determined for the hyp and $\beta$-tub genes (Table 3 ). The scp region was excluded from this analysis because more than two alleles were observed in two of the representative isolates by cloning and sequencing of the respective amplicons. In particular, five and four alleles were revealed for isolates Anthurium and IMI268688, respectively, revealing an unexpected genetic framework for a diploid organism like P. nicotianae.
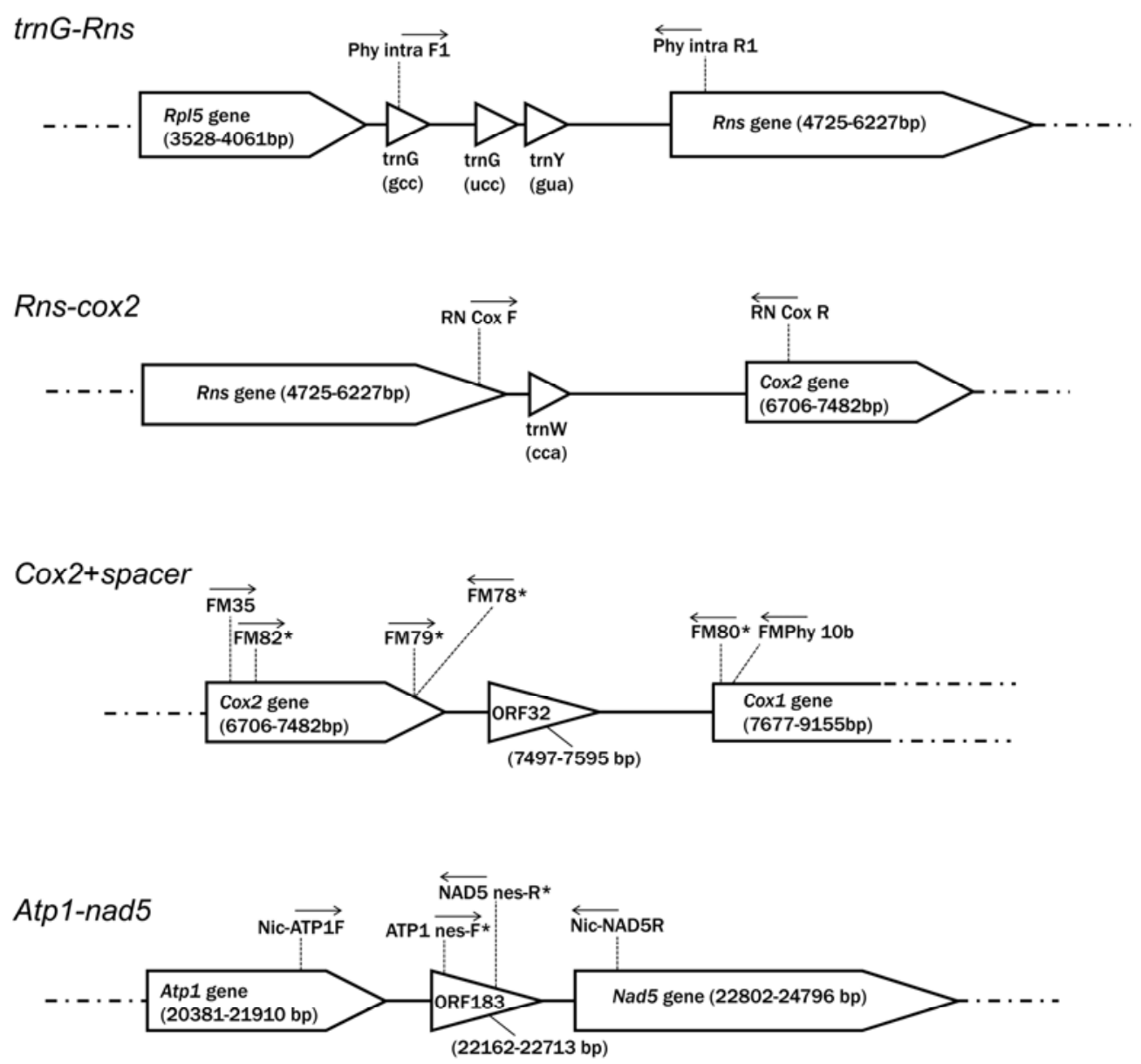

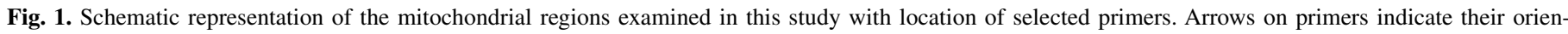

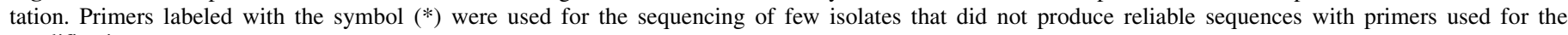
amplification. 
Nonsynonymous substitutions were identified in the hyp locus, with 27 isolates having an SNP in position 101, leading to a change from Cys to Ser. Similarly, 41 isolates had a nonsynonymous change in position 238 of the scp locus leading to a change from Ser to Gly (Supplemental Table 2). Furthermore, a single SNP in position 397 led to a change from Ala to Thr in isolate $\mathrm{P} 3815$. Nonsynonymous substitutions were not observed in the $\beta$-tub gene.

Haplotype analyses. Mitochondrial DNA. Polymorphisms in the four mitochondrial regions partitioned the 96 isolates of the panel into 28,9,13, and 31 haplotypes for regions trnG-rns, rns$\operatorname{cox} 2$, cox $2+$ spacer, and atpl-nad5, respectively (Tables 1 and 3). Haplotype diversity was 0.6243-0.9414 (Table 3) and eight haplotypes were also identified in the coding region of cox 2 gene. The combined data set of the four mitochondrial regions enabled the identification of 50 haplotypes with a high haplotype diversity (0.9735), mainly due to the large number of unique multilocus haplotypes (31). Haplotypes H11 and H38 were the most frequently encountered (Table 1). Based on haplotypes and $\pi$, the intergenic spacers trnG-rns and atpl-nad5 were the most variable regions. In all, 47 of 50 haplotypes were identified analyzing only these two regions.

Nuclear DNA. Four alleles were identified for the hyp region, with a haplotype diversity of 0.4515 (Tables 1 and 3). A higher number of alleles $(n=7)$ were identified for the $\beta$-tub region (Tables 1 and 3). The higher haplotype diversity in the $\beta$-tub gene was mainly determined by heterozygous individuals showing lowfrequency alleles (Table 1). The confidence probability score for each SNP position in the haplotypes determined using PHASE was 1 or 0.97 (in a single case) for the five different runs, indicating a high accuracy of the test.

Phylogenetic analyses. Mitochondrial DNA. Phylogenetic analyses were conducted using the concatenated data set of the four mitochondrial regions because the partition homogeneity test was not significant $(P=0.06)$. The three methods of analysis (maximum parsimony, maximum likelihood, and Bayesian) generated trees with a similar topology (Fig. 2). The 96 isolates (50 haplotypes) were distributed in six main clades largely

TABLE 2. Primers and polymerase chain reaction amplification conditions used in the present study to amplify and sequence mitochondrial and genomic regions of Phytophthora nicotianae

\begin{tabular}{|c|c|c|c|}
\hline Target DNA & Primers $^{\mathrm{a}}$ & Sequence $\left(5^{\prime}-3^{\prime}\right)^{\mathrm{b}}$ & Amplification conditions \\
\hline \multicolumn{4}{|c|}{ Mitochondrial DNA } \\
\hline \multirow[t]{2}{*}{ TrnG-rns } & Phy intra-F1 ${ }^{c}$ & GGTAGAGTATAACCTTGC & \\
\hline & Phy intra-R $1^{\mathrm{c}}$ & ATAGCATTTATTCTGAGCCA & $3 \mathrm{mM} \mathrm{Mg}, 57^{\circ} \mathrm{C}$ \\
\hline & $\mathrm{RN}-\mathrm{CoxR}^{\mathrm{d}}$ & AAACCTAATTGCCAAGGTTC & $3 \mathrm{mM} \mathrm{Mg}, 64^{\circ} \mathrm{C}$ \\
\hline \multirow[t]{4}{*}{ Cox2+spacer } & FM35 & CAGAACCTTGGCAATTAGG & $\ldots$ \\
\hline & FMphy-10be & GCAAAAGCACTAAAAATTAAATATAA & $\ldots$ \\
\hline & FM7 $78^{f}$ & (ACAAATTTCACTACATTGTCC) & $\ldots$ \\
\hline & FM $80^{\mathrm{f}}$ & (AATATCTTTATGATTTGTTGAAA) & $3 \mathrm{mM} \mathrm{Mg}, 54^{\circ} \mathrm{C}$ \\
\hline \multirow[t]{4}{*}{ Atp1-nad5 } & Nic-ATP1F & AACTAATCATTCTAATATTTTAGAA & $\ldots$ \\
\hline & Nic-NAD5R & CAGAACCTTTACGTCCAATAT & $\ldots$ \\
\hline & ATP1nes-F & (AAACAATTTAGATTACGTGGA) & \\
\hline & NAD5 nes-R & (CAAATATCTATTGGTGTTAACAT) & $3 \mathrm{mM} \mathrm{Mg}, 54^{\circ} \mathrm{C}$ \\
\hline \multicolumn{4}{|l|}{ Nuclear DNA } \\
\hline hyp & $\mathrm{I} 11 \mathrm{~F}^{\mathrm{g}}$ & TCGTCBGTGTCCTCBACGTC & \\
\hline & BtubR1 ${ }^{\mathrm{h}}$ & CCTGGTACTGCTGGTACTCAG & $\ldots$ \\
\hline & NtubF1 & (ACGCTTCTTATCTCGAAGATT) & $\ldots$ \\
\hline & NtubR1 & (CTTACGCAGGTCCGAGTTC) & $\ldots$ \\
\hline & NtubF2 & (CTCGGACCTGCAGCTGGA) & $\cdots$ \\
\hline & NtubR2 & (CGTAAACTGTTCGGACACAC) & $2.5 \mathrm{mM} \mathrm{Mg}, 60^{\circ} \mathrm{C}$ \\
\hline
\end{tabular}

${ }^{\text {a }}$ Primers not designed in the present study were from other sources, as indicated below.

${ }^{b}$ Primers reported in parenthesis were only used for sequencing.

${ }^{c}$ Martin and Coffey (43).

${ }^{\mathrm{d}}$ F. N. Martin, unpublished.

e Martin (41)

${ }^{\mathrm{f}}$ Martin and Tooley (44).

g Schena et al. (53).

h Blair et al. (3).

TABLE 3. Summary table showing results from the analyses of mitochondrial and nuclear sequences of Phytophthora nicotianae $e^{\mathrm{a}}$

\begin{tabular}{|c|c|c|c|c|c|c|c|c|c|}
\hline \multirow[b]{2}{*}{ Parameters } & \multicolumn{5}{|c|}{ Mitochondrial DNA } & \multicolumn{4}{|c|}{ Nuclear DNA } \\
\hline & trnG-rns & $r n s-\operatorname{cox} 2$ & cox2-spacer & atp1-nad5 & CMS & hyp & $s c p$ & $\beta-t u b$ & $\mathrm{CNS}$ \\
\hline Isolates & 96 & 96 & 96 & 96 & 96 & 96 & 96 & 95 & 95 \\
\hline Alignment length (bp) & 629 & 577 & 912 & 905 & 3,023 & 241 & 544 & 869 & 1,654 \\
\hline Haplotype/allele diversity & 0.9325 & 0.8132 & 0.6243 & 0.9414 & 0.9735 & 0.4515 & n.d. & 0.7334 & n.d. \\
\hline Polymorphic sites $^{\mathrm{b}}$ & 12 & 4 & 13 & 23 & 52 & 3 & 10 & 11 & 24 \\
\hline Site with gaps & 33 & 120 & 36 & 124 & 313 & 0 & 0 & 0 & 0 \\
\hline
\end{tabular}

${ }^{a}$ CMS = combined mitochondrial sequences, $\mathrm{CNS}=$ combined nuclear sequences, and n.d. = not determined.

${ }^{b}$ Gaps were excluded from the analysis of polymorphic sites. 
corresponding to groups observed in the mitochondrial network (Fig. 3).

Clade N1 consisted of nine haplotypes representing 12 isolates, mainly from ornamental species, that could be separated into two

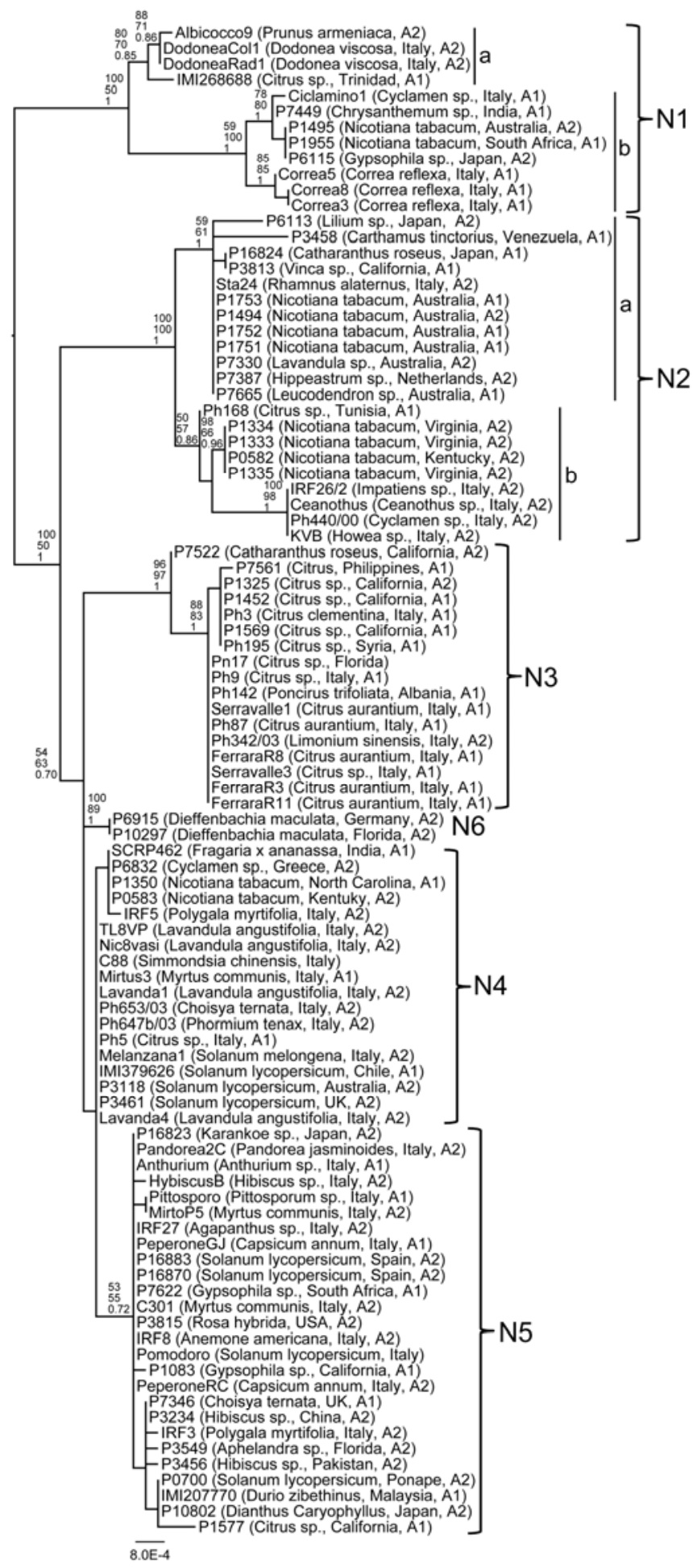

Fig. 2. Phylogenetic relationships among isolates of Phytophthora nicotianae based on the combined data set of sequences of the four mitochondrial regions (trnG-rns, rns-cox2, cox2+spacer, and atp1-nad5). Numbers on nodes represent the statistical support for maximum likelihood (100 replicates, top number), maximum parsimony (1,000 bootstrap replicates, middle number), and Bayesian method (posterior probabilities, bottom number). Per each isolate host, country of origin and mating type are indicated. Numbers preceded by "N" on the right of the tree indicate phylogenetic clades as identified in this study (and correlating as much as possible with clade numbering by Mammella et al. [39]). subclades, 1a and 1b. Among isolates of this group there were 15 SNPs (12 parsimony informative) and 149 sites with gaps. Haplotype diversity within clade N1 was 0.9545 . Two different haplotypes for tobacco isolates from Australia (P1495) and South Africa (P1955) clustered in this group.

Clade N2 consisted of seven haplotypes representing 21 isolates. In all, 18 SNPs (10 parsimony informative) and 30 sites with gaps were observed in this clade, with a haplotype diversity of 0.805 . Isolates from various geographic locations and hosts clustered in this clade, including the majority of isolates from tobacco (8 of 12 isolates) from Australia and the United States (Kentucky and Virginia). Seven SNPs differentiated Australian tobacco isolates (subclade 2a) from those recovered from the United States (subclade 2b) (Fig. 2).

In clade N3, there were nine haplotypes (17 isolates), mainly recovered from citrus (15 isolates) from different geographic locations; two other isolates were from Limonium sinensis (Ph342/03) and Catharanthus roseus (P7522). Isolate Ph342/03 had the same multilocus mitochondrial haplotype (H23) as five isolates from citrus but was the only isolate of this haplotype showing an A2 mating type (Fig. 2). Isolate P7522 represented a unique haplotype and clustered in a single branch basal to the rest of the clade. In total, five SNPs (one parsimony informative) differentiated isolates of this clade, with a haplotype diversity of 0.8603 . However, only two SNPs were observed (one parsimony informative) in the atpl-nad5 region and haplotype diversity dropped to 0.8417 by excluding isolate P7522 from the analysis.

Clades N4 and N5 were very heterogeneous for geographic origin, host, and mating type (Fig. 2). The first clade was represented by 18 isolates ( 9 haplotypes) differentiated by two SNPs and was characterized by a haplotype diversity of 0.8366 . Clade N5 consisted of 15 haplotypes representing 26 isolates and had a haplotype diversity of 0.9015 . Haplotypes in this clade were differentiated by 10 SNPs (2 SNPs parsimony informative) and 89 sites with gaps. Most isolates in clades 4 and 5 were from ornamental and horticultural crops. In particular, all isolates from Solanum spp. clustered within these groups. Clade N6 corresponded to a single haplotype branch for two isolates from D. maculata recovered from Florida and Germany.

Nuclear DNA. The concatenated data set of nuclear sequences utilized to construct a neighbor-joining tree did not reveal any significant clustering with regards to geographic origin of isolates (data not shown). Analysis of distance focused on the host confirmed mitochondrial results, with the clustering of the majority of citrus isolates in a common group. In particular, 12 of 15 citrus isolates grouped in the mitochondrial clade N3 (Fig. 2) also constituted a very uniform group in the nuclear analysis (data not shown). The other three isolates (P1325, P1452, and P1569) of clade N3 shared a common root with the other citrus isolates.

Network analysis. Mitochondrial DNA. The network analysis of haplotypes using the combined data set of mitochondrial sequences showed an inconsistent correlation among haplotype groups and geographic origin of isolates (Table 1; Fig. 3). Interestingly, some haplogroups (H4, H11, H23, H31, H33, H36, H38, and H50) contained isolates of both mating types from different geographic locations (Table 1). Similarly, four isolates from southern Italy (PeperoneGJ and PeperoneRC from Calabria and Lavanda1 and Mirtus3 from Sicily) had the same mitochondrial haplotype but opposite mating types.

A relevant association was observed among hosts of recovery and haplogroups. For example, the majority of isolates from citrus species grouped together, even if recovered from different geographic regions (Italy, California, Florida, Philippines, Syria, and Albania) (Table 1; Fig. 3). Haplotype diversity within all isolates from citrus was 0.9181 ( $\pi$ of 0.00219 ) and dropped to 0.8667 ( $\pi$ of 0.00022 ) when examining only isolates that clustered together. The majority of tobacco isolates grouped in two similar haplotypes (H11 and H17). Other examples of association among host 
of recovery and haplogroups was observed with isolates P10297 and P6915 from D. maculata from Florida and Germany (haplotype H10), isolates P3813 and P16824 recovered from Catharanthus spp. from Japan and California (haplotype H13), and isolates P3461 and P3118 recovered from Solanum lycopersicum from the United Kingdom and Australia (haplotype H31) (Fig. 3).

Nuclear DNA. Analysis of the network generated using data from the hyp nuclear region revealed the presence of four alleles differentiated by single steps (Fig. 4A). The dominant allele (a1) was identified in 76 isolates of $P$. nicotianae from different geographic origins and hosts (Table 1; Fig. 4A). Of these isolates, 59 were homozygous and 17 were heterozygous (Table 1). The majority of citrus isolates had the same allele, a3. Three of the California isolates (P1325, P1452, and P1569) were heterozygous (a1/a3) and shared allele a1 with the other four citrus isolates (Ph168, Ph5, P1577, and IMI268688) that did not group together in the mitochondrial network (Table 1; Fig. 4A). Tobacco isolates from the United States all had the same hyp allele (a3). One of these isolates from Kentucky (P0583) was heterozygous (a2/a3) and shared allele a2 with tobacco isolates from Australia that were all heterozygous (a1/a2). These latter isolates shared allele a1 with the two tobacco isolates (P1495 and P1955) from Australia and South Africa, respectively, that grouped separately based on mitochondrial analysis. A unique allele (a4) was found for a heterozygous (a1/a4) isolate collected in Italy from Polygala myrtifolia (Table 1; Fig. 4A).

Seven alleles, separated by one or two steps (in most of the cases) or five steps (a6 and a7), were identified with the $\beta$-tub gene (Fig. 4B). The distribution of alleles was not related to the geographic origin of isolates. The most frequent allele (a1) was shared by 57 isolates, and only 5 of these were homozygous (Table 1). All citrus isolates grouping together in the mitochondrial network were heterozygous and shared the same alleles (a1/a3). Allele a3 joined this citrus group as a single homozygous citrus isolate $(\mathrm{Ph} 5)$ that grouped separately based on mitochondrial analysis. Two other citrus isolates (P1577 and Ph168) were homozygous (a4) and shared this allele with the heterozygous isolate IMI268688 (a4/a6) that contained the unique allele a6 (Table 1; Fig. 4B). The tobacco isolates from Australia were almost all heterozygous (a1/a3), except for P1751 (a3) and P1495 (a4). This latter allele joined homozygous tobacco isolates from the United States ( $\beta$ tubH4) and a single heterozygous ( $\beta$ tubH1/ $\beta$ tubH4) isolate (P0583) from Kentucky. The two isolates from $D$. maculata recovered from Florida and Germany were heterozygous (a4/a7) and had the unique allele a7 (Table 1).

Population structure and inbreeding analysis. A significant genetic structure was determined with AMOVA among host of recovery with both combined mitochondrial haplotypes and $\beta$-tub

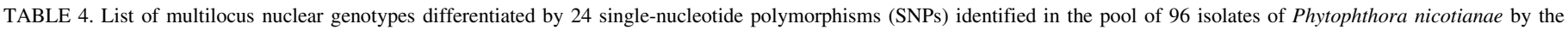
analysis of hypothetical protein (hyp), SCP-like extra cellular protein $(s c p)$, and $\beta$-tubulin $\left(\beta\right.$-tub) genes ${ }^{\mathrm{a}}$

\begin{tabular}{|c|c|c|c|c|c|c|c|c|c|c|c|c|c|c|c|c|c|c|c|c|c|c|c|c|c|}
\hline \multirow[b]{3}{*}{ Gen } & \multirow[b]{3}{*}{$\mathrm{Fr}$} & \multicolumn{24}{|c|}{ SNP sites } \\
\hline & & \multicolumn{3}{|c|}{ hyp } & \multicolumn{10}{|c|}{$s c p$} & \multicolumn{11}{|c|}{$\beta-t u b$} \\
\hline & & 85 & 101 & 181 & 331 & 337 & 451 & 479 & 496 & 502 & 574 & 638 & 691 & 727 & 814 & 862 & 886 & 1147 & 1228 & 1252 & 1375 & 1420 & 1558 & 1567 & 1588 \\
\hline G1 & 3 & G & $\mathrm{T}$ & $\mathrm{C}$ & $\mathrm{C}$ & A & $\mathrm{G}$ & A & $\mathrm{C}$ & G & G & G & G & G & $\mathrm{C}$ & $\mathrm{C}$ & $\mathrm{C}$ & G & G & $\mathrm{C}$ & $\mathrm{C}$ & $\mathrm{R}$ & G & $\mathrm{T}$ & G \\
\hline G2 & 1 & . & W & . & . & G & . & G & . & . & . & . & A & . & . & . & . & . & . & . & . & G & . & . & . \\
\hline G3 & 1 & . & . & . & $\mathrm{Y}$ & $\mathrm{R}$ & . & $\mathrm{R}$ & $\mathrm{Y}$ & $\mathrm{R}$ & $\mathrm{R}$ & . & $\mathrm{R}$ & $\mathrm{K}$ & $\mathrm{T}$ & . & . & . & . & . & $\mathrm{T}$ & G & . & . & A \\
\hline G4 & 1 & . & . & . & . & G & . & G & . & . & . & . & A & . & $\mathrm{Y}$ & $\mathrm{Y}$ & $\mathrm{Y}$ & . & . & . & $\mathrm{Y}$ & G & . & . & $\mathrm{R}$ \\
\hline G5 & 1 & . & . & . & $\mathrm{Y}$ & $\mathrm{R}$ & . & $\mathrm{R}$ & $\mathrm{Y}$ & $\mathrm{R}$ & $\mathrm{R}$ & . & $\mathrm{R}$ & $\mathrm{K}$ & $\mathrm{Y}$ & . & . & . & . & . & $\mathrm{Y}$ & . & . & . & $\mathrm{R}$ \\
\hline G6 & 1 & . & . & . & . & $\mathrm{R}$ & . & $\mathrm{R}$ & . & . & . & . & $\mathrm{R}$ & . & . & . & . & . & . & . & $\mathrm{Y}$ & . & . & . & . \\
\hline G7 & 4 & . & . & . & . & . & . & . & . & . & . & . & . & . & . & . & . & . & . & . & $\mathrm{Y}$ & $\mathrm{G}$ & . & . & . \\
\hline G8 & 1 & . & . & . & . & $\mathrm{R}$ & $\mathrm{R}$ & $\mathrm{R}$ & . & . & . & . & $\mathrm{R}$ & . & $\mathrm{T}$ & . & . & . & . & . & $\mathrm{Y}$ & $\mathrm{G}$ & . & . & $\mathrm{R}$ \\
\hline G9 & 2 & . & . & . & . & . & . & . & . & . & . & . & . & . & $\mathrm{T}$ & . & . & $\mathrm{R}$ & $\mathrm{R}$ & $\mathrm{Y}$ & $\mathrm{Y}$ & G & $\mathrm{R}$ & $\mathrm{Y}$ & $\mathrm{R}$ \\
\hline G10 & 5 & $\mathrm{R}$ & . & . & . & . & . & . & . & . & . & . & . & . & . & . & . & . & . & . & $\mathrm{Y}$ & $\mathrm{G}$ & . & . & . \\
\hline G11 & 2 & $\mathrm{R}$ & . & . & . & . & . & . & . & . & . & . & . & . & . & . & . & . & . & . & $\mathrm{T}$ & $\mathrm{G}$ & . & . & . \\
\hline G12 & 2 & . & W & . & . & . & . & . & . & . & . & . & . & . & . & $\mathrm{Y}$ & $\mathrm{Y}$ & . & . & . & . & $\mathrm{G}$ & . & . & . \\
\hline G13 & 2 & . & . & . & . & $\mathrm{R}$ & . & $\mathrm{R}$ & . & . & . & . & $\mathrm{R}$ & . & $\mathrm{Y}$ & . & . & . & . & . & $\mathrm{Y}$ & . & . & . & $\mathrm{R}$ \\
\hline G14 & 1 & $\mathrm{R}$ & . & . & . & . & . & . & . & . & . & . & . & . & . & . & . & . & . & . & . & $\mathrm{G}$ & . & . & . \\
\hline G15 & 1 & A & . & . & . & $\mathrm{R}$ & . & $\mathrm{R}$ & . & . & . & . & A & . & . & . & . & . & . & . & . & $\mathrm{G}$ & . & . & . \\
\hline G16 & 5 & . & . & . & . & $\mathrm{R}$ & . & $\mathrm{R}$ & . & . & . & . & . & . & . & . & . & . & . & . & $\mathrm{Y}$ & $\mathrm{G}$ & . & . & . \\
\hline G17 & 3 & . & . & . & . & $\mathrm{R}$ & . & $\mathrm{R}$ & . & . & . & . & $\mathrm{R}$ & . & $\mathrm{T}$ & . & . & . & . & . & $\mathrm{T}$ & $\mathrm{G}$ & . & . & A \\
\hline G18 & 5 & . & A & . & . & . & . & . & . & . & . & . & . & . & $\mathrm{T}$ & . & . & . & . & . & $\mathrm{T}$ & $\mathrm{G}$ & . & . & A \\
\hline G19 & 1 & $\mathrm{R}$ & . & . & . & $\mathrm{R}$ & . & $\mathrm{R}$ & . & . & . & . & $\mathrm{R}$ & . & . & . & . & . & . & . & $\mathrm{Y}$ & $\mathrm{G}$ & . & . & . \\
\hline G20 & 3 & . & W & . & . & $\mathrm{R}$ & . & $\mathrm{R}$ & . & . & . & . & $\mathrm{R}$ & . & . & . & . & . & . & . & $\mathrm{Y}$ & $\mathrm{G}$ & . & . & . \\
\hline G22 & 1 & . & A & . & . & $\mathrm{G}$ & . & $\mathrm{G}$ & . & . & . & . & A & . & . & . & . & . & . & . & $\mathrm{Y}$ & $\mathrm{G}$ & . & . & . \\
\hline G23 & 1 & . & A & . & . & . & . & . & . & . & . & . & . & . & . & . & . & . & . & . & $\mathrm{Y}$ & $\mathrm{G}$ & . & . & . \\
\hline G24 & 3 & . & . & . & . & $\mathrm{G}$ & . & $\mathrm{G}$ & . & . & . & . & A & . & $\mathrm{Y}$ & . & . & . & . & . & $\mathrm{Y}$ & $\mathrm{G}$ & . & . & $\mathrm{R}$ \\
\hline G25 & 1 & $\mathrm{R}$ & W & . & . & . & . & . & . & . & . & . & . & . & $\mathrm{Y}$ & . & . & . & . & . & $\mathrm{Y}$ & $\mathrm{G}$ & . & . & $\mathrm{R}$ \\
\hline G26 & 7 & . & . & . & . & $\mathrm{G}$ & . & $\mathrm{G}$ & . & . & . & . & A & . & $\mathrm{T}$ & . & . & . & . & . & $\mathrm{T}$ & $\mathrm{G}$ & . & . & A \\
\hline G27 & 1 & . & . & . & . & $\mathrm{G}$ & . & $\mathrm{G}$ & . & . & . & . & $\mathrm{R}$ & . & . & . & . & . & . & . & $\mathrm{T}$ & $\mathrm{G}$ & . & . & . \\
\hline G28 & 4 & . & . & . & . & $\mathrm{R}$ & . & $\mathrm{R}$ & . & . & . & . & $\mathrm{R}$ & . & . & . & . & . & . & . & $\mathrm{Y}$ & $\mathrm{G}$ & . & . & $\mathrm{R}$ \\
\hline G29 & 1 & . & W & $\mathrm{Y}$ & . & $\mathrm{R}$ & . & . & . & . & . & . & . & . & $\mathrm{Y}$ & . & . & . & . & . & $\mathrm{Y}$ & $\mathrm{G}$ & . & . & $\mathrm{R}$ \\
\hline G30 & 1 & . & . & . & . & $\mathrm{R}$ & . & $\mathrm{R}$ & . & . & . & . & $\mathrm{R}$ & . & . & . & . & . & . & . & $\mathrm{Y}$ & $\mathrm{G}$ & . & . & . \\
\hline G31 & 2 & . & . & . & $\mathrm{Y}$ & $\mathrm{R}$ & . & $\mathrm{R}$ & $\mathrm{Y}$ & $\mathrm{R}$ & $\mathrm{R}$ & . & $\mathrm{R}$ & $\mathrm{K}$ & $\mathrm{Y}$ & . & . & . & . & . & $\mathrm{Y}$ & $\mathrm{G}$ & . & . & $\mathrm{R}$ \\
\hline G32 & 1 & . & W & . & . & G & . & $\mathrm{R}$ & . & . & . & $\mathrm{R}$ & $\mathrm{R}$ & . & . & . & . & . & . & . & $\mathrm{Y}$ & $\mathrm{G}$ & . & . & . \\
\hline G33 & 2 & . & . & . & . & $\mathrm{R}$ & . & $\mathrm{R}$ & . & . & . & . & A & . & $\mathrm{Y}$ & $\mathrm{Y}$ & $\mathrm{Y}$ & . & . & . & $\mathrm{Y}$ & $\mathrm{G}$ & . & . & $\mathrm{R}$ \\
\hline G34 & 1 & . & . & . & . & $\mathrm{R}$ & . & $\mathrm{R}$ & . & . & . & . & $\mathrm{R}$ & . & $\mathrm{Y}$ & $\mathrm{Y}$ & $\mathrm{Y}$ & . & . & . & $\mathrm{Y}$ & $\mathrm{G}$ & . & . & $\mathrm{R}$ \\
\hline G35 & 4 & . & . & . & . & $\mathrm{G}$ & . & $\mathrm{G}$ & . & . & . & . & A & . & . & $\mathrm{Y}$ & $\mathrm{Y}$ & . & . & . & . & $\mathrm{G}$ & . & . & . \\
\hline G36 & 1 & . & . & . & . & $\mathrm{R}$ & . & $\mathrm{R}$ & . & . & . & . & $\mathrm{R}$ & . & . & $\mathrm{Y}$ & $\mathrm{Y}$ & . & . & . & $\mathrm{Y}$ & $\mathrm{G}$ & . & . & . \\
\hline G37 & 1 & . & . & . & . & $\mathrm{G}$ & . & $\mathrm{G}$ & . & . & . & . & $\mathrm{R}$ & . & . & . & . & . & . & . & . & $\mathrm{G}$ & . & . & . \\
\hline G38 & 1 & . & . & . & . & $\mathrm{R}$ & . & $\mathrm{R}$ & . & . & . & . & $\mathrm{R}$ & . & $\mathrm{Y}$ & . & . & . & . & . & $\mathrm{T}$ & $\mathrm{G}$ & . & . & $\mathrm{R}$ \\
\hline G39 & 1 & . & . & . & . & . & . & $\mathrm{R}$ & . & . & . & . & $\mathrm{R}$ & . & $\mathrm{T}$ & . & . & . & . & . & $\mathrm{T}$ & $\mathrm{G}$ & . & . & A \\
\hline G40 & 5 & . & . & . & . & . & . & . & . & . & . & . & . & . & . & . & . & . & . & . & $\mathrm{T}$ & G & . & . & . \\
\hline Obs & $\ldots$ & 0.10 & 0.09 & 0.01 & 0.04 & 0.45 & 0.01 & 0.46 & 0.04 & 0.04 & 0.04 & 0.01 & 0.40 & 0.04 & 0.20 & 0.11 & 0.11 & 0.02 & 0.02 & 0.02 & 0.58 & 0.07 & 0.02 & 0.02 & 0.23 \\
\hline
\end{tabular}

a Order and nucleotide position of the loci refer to the combined nuclear sequences. Gen = genotype, $\mathrm{Fr}=$ frequency, and Obs $=$ observed heterozygosity. 
and hyp nuclear alleles which explained 44.82, 12.07, and 29.6\% of the total variability, respectively (Tables 5 and 6 ). By contrast, only $6.52 \%$ (mitochondrial haplotypes), $4.65 \%$ ( $\beta$-tub), and $11.19 \%$ (hyp) of the variability was explained by the geographic origin of the isolates (Tables 5 and 6).

Inbreeding coefficients $\left(\mathrm{F}_{\mathrm{IS}}\right)$ were slightly positive, with both gene alleles for populations from specialized field crops (Citrus, Nicotiana, and Solanum spp.) (Table 7). Significantly lower F $_{\text {IS }}$ values were observed for potted ornamental species in the nursery, suggesting a higher level of outbreeding within this population (Table 7).

\section{DISCUSSION}

Four mitochondrial markers and three nuclear coding regions were used in this research to study 96 isolates of Phytophthora nicotianae representing a wide range of hosts and geographic locations. Among mitochondrial regions, the rns-cox 2 and $t r n G-$ rns markers spanned regions (trnW-cox 2 and trnY-rns) analyzed in our previous work (39) but included an additional 262 and 275 bp of data, respectively. For the rns-cox2 locus, the additional sequence data did not improve haplotype identification, whereas the additional sequence data from the trnG-rns region improved resolution of haplotypes. The cox $2+$ spacer region identified 13 different haplotypes, with 8 of them separated by eight SNPs in the coding region. Intraspecific variability within this gene has been identified for Phytophthora spp., including two isolates of $P$. nicotianae (44). In all, 9 of 14 species with multiple isolates showed genetic variability at an intraspecific level for the cox 2 gene (44). The atpl-nad5 region was the most variable among the four mitochondrial regions analyzed in the present work because it allowed the identification of 31 haplotypes differentiated by 23 SNPs as well as 124 sites with gaps and length variations in homopolymeric regions.

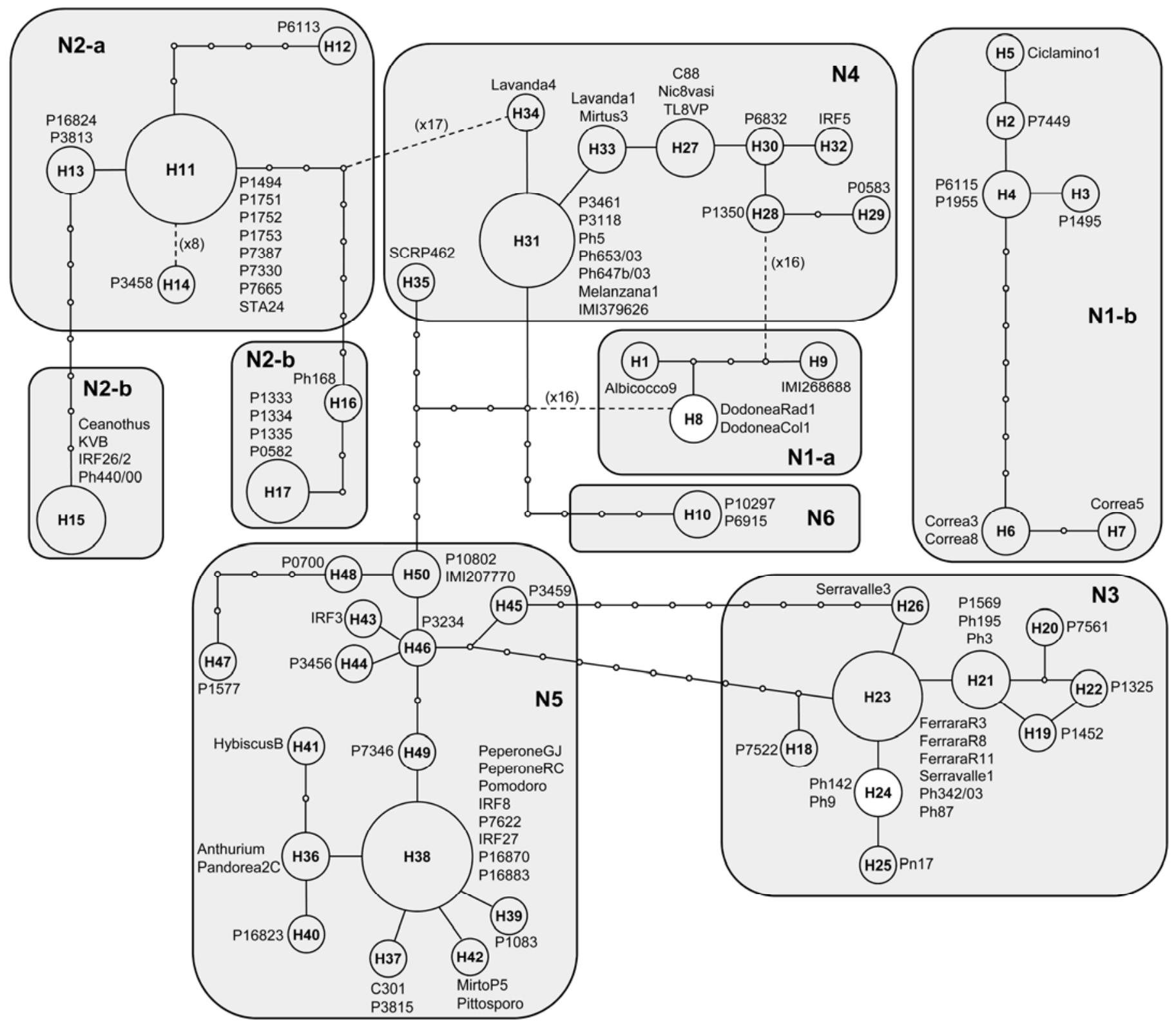

Fig. 3. Haplotype network based on the combined sequences of the mitochondrial data (trnG-rns, rns-cox2, cox2+spacer, and atp1-nad5) of the 96 Phytophthora nicotianae isolates analyzed in the present study. The network was constructed using a statistical parsimony algorithm implemented in TCS 1.21 (10). Per each haplotype $(\mathrm{H})$, the size of each circle represents its relative frequency and the corresponding isolates are indicated. Delimitated groups of haplotypes marked with the letter code "N" represents genetic groups according to the phylogenetic analysis (Fig. 2). The haplotypes were directly connected without dots when differing by a single change. Every additional putative change was indicated by adding a dot or by indicating the number of steps on dotted lines. Haplotypes grouping in the subclade N1-b (Fig. 2) were not linked to any other group of the network, considering a connection limit of $95 \%$. 
The phylogenetic analysis of the combined mitochondrial data revealed the existence of separate phylogenetic groups that were consistent with three different phylogenetic methods and produced clades largely confirming those reported by Mammella et al. (39). However, the analysis of a larger portion of the genome (10\% of the total) and the increased number of isolates enabled the identification of a higher number of mitochondrial haplotypes (50 haplotypes) and a more accurate delineation of genetic groups with the identification of a new clade (N6) and some subclades. It is worth noting that almost all the observed haplotypes (47 haplotypes) were identified by analyzing two mitochondrial regions (trnG-rns and atpl-nad5). These two regions could represent a valuable tool for the analysis of the worldwide distribution of $P$. nicotianae haplotypes without the need for extensive sequencing of additional markers.

The analysis of both mitochondrial and nuclear markers revealed the absence of a relevant geographic structure, with $P$. nicotianae haplotypes or alleles shared among different locations
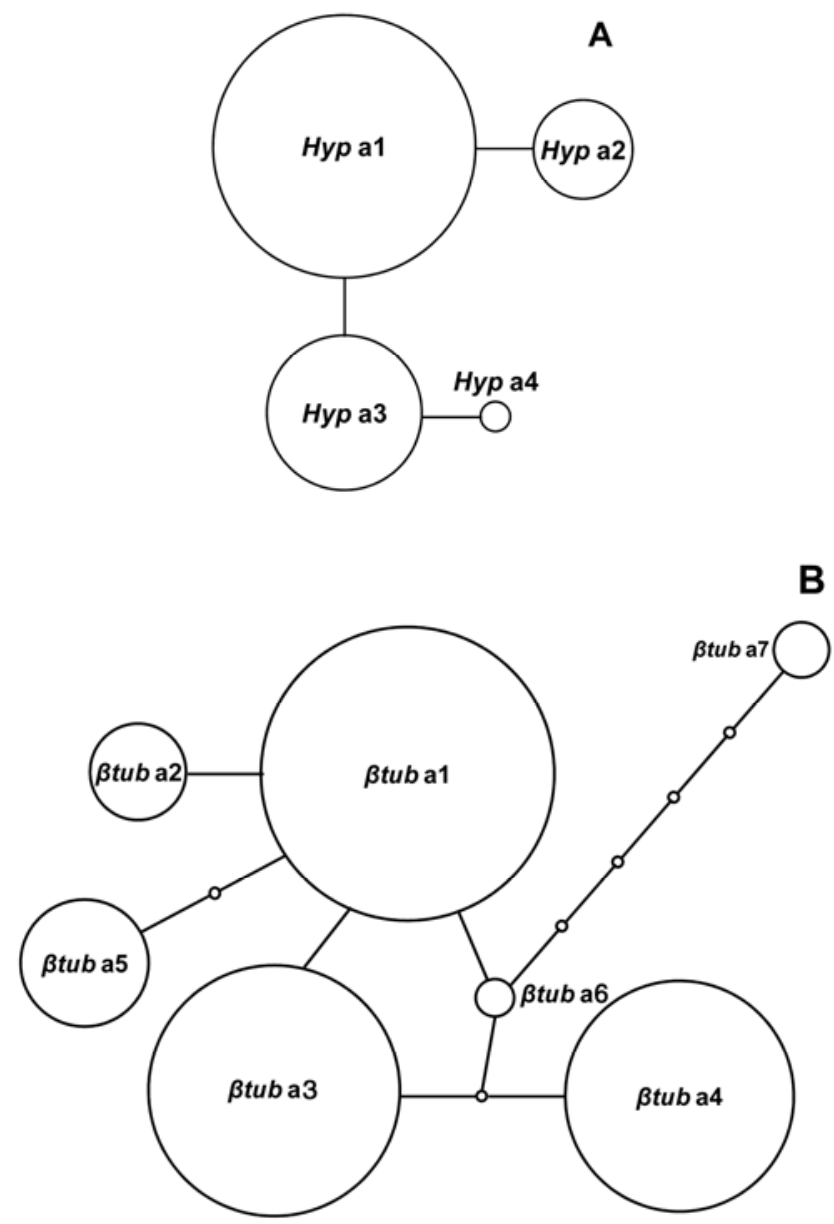

Fig. 4. Network of alleles generated for the A, nuclear hypothetical conserved protein (hyp) and $\mathbf{B}, \beta$-tubulin $(\beta$-tub) genes of Phytophthora nicotianae, using the statistical parsimony algorithm implemented in TCS 1.21 (10). Isolate codes belonging to each group are listed in Table 1. as in a typical panmictic distribution resulting from recurring events of migration. In particular, AMOVA analysis of mitochondrial haplotypes showed a very limited contribution of the geographic origin of isolate to the observed variability, with a fixation index $\left(\mathrm{F}_{\mathrm{ST}}\right)$ of 0.0652 . In agreement with AMOVA, all identified mitochondrial phylogenetic and network groups contained isolates from different countries and the most frequent haplotypes (H11 and H38) were shared among isolates from different geographic origins. Mitochondrial results were largely confirmed by the analysis of three nuclear loci, although these markers were less effective in differentiating closely related isolates. In particular, AMOVA applied to nuclear alleles confirmed a negligible role of geographic origin in determining total variability even if a quite high $\mathrm{F}_{\mathrm{ST}}$ value was obtained with the hyp gene. However, hyp was the least variable gene among those analyzed in the present study and its $\mathrm{F}_{\mathrm{ST}}$ value was indirectly influenced by the host, considering that the Australian population had a major role in determining the final value and was largely sourced from a single host (tobacco). In agreement with AMOVA analyses the nuclear gene networks exhibited alleles widely distributed among isolates from different geographic origins, even if they were differentiated by few steps. For instance, the most frequent alleles (hyp a1 and $\beta$-tub a1) were represented by isolates from different regions. Furthermore, although an accurate phylogenetic analysis was not possible for the concatenated data set of nuclear sequences due to their high level of heterozygosity, the constructed neighbor-joining tree confirmed the absence of significant clustering as far as the geographic origin of isolates was concerned.

A significant structuring of populations was revealed with mitochondrial and nuclear markers in relation to the host. A high $\mathrm{F}_{\mathrm{ST}}$ value (0.4482) was obtained from the AMOVA analyses of mitochondrial haplotypes but significant values were also obtained with $\beta$-tub and hyp alleles. Furthermore, the mitochondrial phylogenetic tree and network analysis showed a relevant grouping of isolates from the same host species. The majority of citrus isolates (15 of 19) clustered together, regardless of their geographic origin (Philippines, Syria, Albania, California, Florida, and Italy). These isolates were characterized by a low level of $\pi$ that was limited to two SNPs in the atpl-nad5 region and length variation in some homopolymeric $\mathrm{T}$ regions. A similar clustering of isolates recovered from the same host was observed for eight isolates from tobacco originating from Australia and United States (Kentucky and Virginia), although a higher genetic variation (seven SNPs) differentiated these isolates. Concordant results were also obtained for isolate from Solanum spp. that clustered in the two related clades 4 and 5 and for different ornamental species, despite the limited number of isolates from each host that prevented accurate evaluations. In agreement with mitochondrial data, the hyp region revealed that the majority of citrus isolates clustering in the N3 mitochondrial group also shared the same hyp a3 allele. Only three isolates from California were heterozygous (a1/a3) and shared the additional allele hyp a1 with other four citrus isolates that did not group together in the mitochondrial DNA analysis. These data reinforced the association among genetic grouping and host of origin, because the few citrus isolates that appeared genetically distant on the basis of the mitochondrial DNA were actually linked at the hyp nuclear level.

TABLE 5. Analysis of molecular variance (AMOVA) of Phytophthora nicotianae populations based on multilocus mitochondrial genotypes

\begin{tabular}{|c|c|c|c|c|c|c|}
\hline Source of variation ${ }^{a}$ & df & Sum of squares & Variance components & Variation $(\%)$ & Fixation index $\left(\mathrm{F}_{\mathrm{ST}}\right)$ & $P$ value \\
\hline \multicolumn{7}{|l|}{ Host genus } \\
\hline Among all populations & 37 & $2,032.943$ & 15.25412 & 44.82 & 0.4482 & 0.0000 \\
\hline Within populations & 57 & $1,070.299$ & 18.7771 & 55.18 & $\ldots$ & $\ldots$ \\
\hline \multicolumn{7}{|l|}{ Geographic origin } \\
\hline Among all populations & 4 & 259.508 & 2.19087 & 6.52 & 0.0652 & 0.00489 \\
\hline Within populations & 91 & $2,856.169$ & 31.38647 & 93.48 & $\ldots$ & $\ldots$ \\
\hline
\end{tabular}

a AMOVA considering originating host genus (Table 1) or geographic origin of isolates (Africa, America, Asia, and Europe). 
Similar results were also obtained with the $\beta$-tub nuclear region; all citrus isolates that grouped together in the mitochondrial network were heterozygous (a1/a3) and shared the allele $\beta$-tub a3 with the homozygous citrus isolate $\mathrm{Ph} 5$ that grouped separately in the mitochondrial analysis. In accordance with previous results, the neighbor-joining tree constructed for the concatenated nuclear data set confirmed the clustering of the majority of citrus isolates in a common group. Tobacco isolates were also genetically similar because they shared at least one allele of the hyp gene. With the $\beta$-tub gene, a single tobacco isolate from Australia did not share any allele with other isolates.

The existence of a significant structuring based on the host of recovery could appear in contrast with the abovementioned inconsistent geographic structuring and polyphagy of $P$. nicotianae. However, a specific association among molecular groups and host of recovery has been reported for isolates causing black shank in tobacco that were differentiated from other $P$. nicotianae isolates (11). Furthermore, considerable evidence supports host preference by some isolates of $P$. nicotianae (15). For instance, an isolate from okra was not pathogenic to Citrus spp. and vice versa (14). Similarly, isolates from Citrus spp. were more virulent on roots of rough lemon than isolates from petunia, tomato, walnut, silk tree, jojoba, hibiscus, and peach although, in another study, tomato plants exhibited high susceptibility to many isolates, including Citrus isolates $(4,45)$. These authors suggested that the degree of susceptibility among hosts is not clear but the greatest degree of virulence is commonly shown by isolates on their own host.

The absence of a geographic structuring and the concurrent existence of a significant structuring in relation to the hosts or origin could be indicative of extensive phenomena of migration of the isolates via plant material or host adaptation. Although specific pathogenicity tests are needed to evaluate the virulence of groups identified in the present study on different hosts and determine whether molecular groupings can be taken as evidence of physiological races or pathotypes, it can be hypothesized that $P$. nicotianae isolates have been spread worldwide with infected plant material and, afterward, lineages may have progressively diverged. In this context, a major role could have been played by the globalization of the nursery trade, with particular emphasis to the sector of potted ornaments. For example, isolates from $D$. maculata from Germany and Florida shared the same mitochondrial haplotype and nuclear multilocus genotype. The role of the nursery trade in the spreading of Phytophthora inoculum has been investigated for $P$. ramorum, the causative agent of sudden oak death $(25,58)$, and similar routes are likely for other Phytophthora spp. In particular, $P$. nicotianae has been widely recovered in nurseries during recent surveys and its long-distance movement can likely be facilitated by its broad host range, currently with more than 250 plant genera in 90 families, including a large number of ornamentals $(7,30,47,49,56,63)$.

The high number of nuclear genotypes identified $(n=40)$, with more than half of them $(n=21)$ unique, and the heterozygosity observed in all loci analyzed seem to indicate a quite high frequency of genetic exchange in P. nicotianae, with at least some of the isolates examined in this study originating from a sexually reproducing population. The worldwide diffusion of this species and its broad range of host surely play an important role in favoring this high level of recombination. Indeed, lower levels of diversity were reported for other heterothallic species of Phytophthora, including $P$. infestans (1) and P. capsici $(19,20)$. In this study, isolates from field crops (Citrus, Nicotiana, and Solanum spp.) were characterized by slightly positive inbreeding coefficients $\left(\mathrm{F}_{\mathrm{IS}}\right)$ with both $\beta$-tub and hyp markers. This result is in line with expectations for a heterothallic species such as $P$. nicotianae (23) but seems to be in contrast with previous reports, indicating that sexual recombination is unlikely to serve as a major mechanism enhancing the genetic diversity of the pathogen in tobacco fields $(36,50)$. Similar data are available for populations of $P$. nicotianae in citrus groves, where A1 is the prevalent and often the sole mating type (6). However, it can be hypothesized that isolates from specialized cultivation are the result of asexually propagated heterozygous clones, adapted to a specific host. For example, most citrus isolates from southern Italy had the same multilocus genotype (homozygous and heterozygous for hyp and $\beta$-tub gene, respectively), were all mating type A1, and all had very closely related mitochondrial haplotypes, suggesting that homozygous and heterozygous loci were fixed in a clonal population. Although larger numbers of isolates collected from each specific host species would be necessary to confirm these speculations, fixed heterozygosity in clonal populations has been already identified in Phytophthora spp. The analyses of six polymorphic SNP loci in $P$. capsici isolates from costal Peru revealed the same heterozygous genome (PcPE-1) among the population, suggesting the widespread diffusion of a single clonal lineage (32) that was also predominant in the Amazonian high jungle of Peru (31). Similarly, the analysis of a $P$. capsici population in Argentina indicated that $87 \%$ of the isolates had the same multilocus genotype, which was fixed for heterozygosity at seven of the eight SNP sites (20). Completely different populations were found in United States and South Africa with many unique genotypes, suggesting a primary role of sexual recombination $(19,37)$.

A different behavior was revealed for $P$. nicotianae isolates collected from potted ornamentals in nursery production, where many different plant species are grown together, favoring the meeting of different genetically distant isolates of $P$. nicotianae.

TABLE 7. Inbreeding coefficients $\left(\mathrm{F}_{\mathrm{IS}}\right)$ calculated for three different Phytophthora nicotianae populations sourced from open field cultures (Citrus, Nicotiana, and Solanum spp.) and for isolates from potted ornamental species in the nursery (Ornamentals)

\begin{tabular}{lcc}
\hline & \multicolumn{2}{c}{$\mathrm{F}_{\mathrm{IS}}$} \\
\cline { 2 - 3 } Population & $\beta$-tub gene & hyp genes \\
\hline Citrus spp. & 0.11561 & 0.63265 \\
Nicotianae spp. & 0.40976 & 0.43103 \\
Solanum spp. & 0.42149 & n.d. $^{\mathrm{a}}$ \\
Ornamentals & -0.10557 & 0.37857 \\
\hline
\end{tabular}

a n.d. = not determined.

TABLE 6. Analysis of molecular variance (AMOVA) of Phytophthora nicotianae populations based on the $\beta$-tubulin and hypothetical protein (in parenthesis values) genotypes

\begin{tabular}{|c|c|c|c|c|c|c|}
\hline Source of variation ${ }^{\mathrm{a}}$ & df & Sum of squares & Variance components & Variation $(\%)$ & Fixation index $\left(\mathrm{F}_{\mathrm{ST}}\right)$ & $P$ value \\
\hline \multicolumn{7}{|l|}{ Host genus } \\
\hline Among individuals within populations & $56(57)$ & $45.500(14.132)$ & $0.04835(0.07189)$ & $5.56(28.75)$ & $\ldots$ & $\ldots$ \\
\hline \multicolumn{7}{|l|}{ Geographic origin } \\
\hline Among all populations & $4(4)$ & $8.703(4.894)$ & $0.04076(0.02859)$ & $4.65(11.19)$ & $0.04648(0.11193)$ & $0.09482(0.01271)$ \\
\hline Among individuals within populations & $90(91)$ & $86.076(31.804)$ & $0.12031(0.12266)$ & $13.72(48.02)$ & $\ldots$ & $\ldots$ \\
\hline Within individuals & $95(96)$ & $68.000(10.000)$ & $0.71579(0.10417)$ & $81.63(40.78)$ & $\ldots$ & $\ldots$ \\
\hline
\end{tabular}

a AMOVA considering originating host genus (Table 1) or geographic origin of isolates (Africa, America, Asia, and Europe). 
These isolates were characterized by a lower inbreeding coefficient (higher level of heterozygosis) compared with isolate groups from Citrus, Nicotiana, and Solanum spp. In particular, the inbreeding coefficient determined with the $\beta$-tub gene was negative, indicating heterozygote excess as compared with the Hardy-Weinberg expectations. In agreement with the considerations above, some isolates recovered from ornamentals in Sicily (southern Italy) were characterized by opposite mating type, the same mitochondrial haplotype, and different multilocus genotypes. These results suggest that nursery populations significantly increase genetic recombination within $P$. nicotianae and play an important role in the evolution of the species.

In the present study, PCR products cloned and sequenced for the scp region showed an unexpected genetic framework for a diploid organism such as $P$. nicotianae because more than two alleles were identified for isolates recovered from Anthurium (five alleles observed) and IMI268688 (four alleles). A possible explanation could be that $s c p$ belongs to a gene family, as already reported for other $P$. nicotianae genes (57). However, a single locus (PPTG_11765.1) with a high homology (99\% identity) was retrieved by blasting $s c p$ sequences obtained in the present study against the complete set of $P$. nicotianae transcripts from the genome project (http://www.broadinstitute.org/annotation/genome/ Phytophthora_parasitica). Outcrossing could also have played a role in determining the unexpected framework. Recently, the genetic characterization of $P$. ramorum single-oospore progeny of crosses between a European A1 isolate and North American or European A2 isolates revealed a considerable number of nonMendelian inheritance events (61). This included inheritance of more than two alleles at a locus and noninheritance of alleles from one parent at another locus. Single-oospore progenies displayed aberrant genomic and phenotypic variation due to meiotic irregularities but also differences in DNA content of singleoospore progeny and variation as a result of post-meiotic genomic rearrangements. Similarly, trisomy and multiple alleles for coding region were observed in $P$. infestans $(48,60)$ and $P$. cinnamomi (13). The possibility of different meiotic rearrangements has been also demonstrated in the related Pythium sylvaticum (40).

In conclusion, a combined analysis of mitochondrial and nuclear markers has been applied in the present study to characterize Phytophthora nicotianae. Using these approaches, it has been possible to generate an overview about its global population structure in relation to geographic origin and hosts, leading to the formulation of hypotheses about preferential reproduction systems and the role of nurseries and trading of propagation material in the evolution and distribution of the species. Considering the level of variation identified in the approximately $1,600 \mathrm{bp}$ screened in the present study, the recent release of the whole genome of $P$. nicotianae (http://www.broadinstitute.org/annotation/genome/ Phytophthora_parasitica) would provide an inexhaustible resource for marker development. The future development of new markers in association with the analysis of a large number of isolates sampled according to specific schemes will enable the characterization of the genetic structure of individual populations of $P$. nicotianae and accurately determine migration pathways and the center of origin of this cosmopolitan plant pathogen. Furthermore, repetitive sampling of the same population over longer time frames could be useful to determine the incidence of sexual and clonal reproduction within specific sites, as well as to track introductions of new genotypes and their effect on the established population.

\section{ACKNOWLEDGMENTS}

This work was partially funded by MIUR-FIRB 2010 "Metagenomic strategies to assess genetic diversity in soil-borne Phytophthora species." Much of this research was completed by M. A. Mammella while working in the laboratory of F. N. Martin and partially supported by United States
Department of Agriculture Agriculture and Food Research Initiative Plan Biosecurity Competitive Grant 2007-55605-17835 and 2008-5560518773. We thank F. Mercati (Dipartimento di Agraria, Università degli Studi Mediterranea, Reggio Calabria, Italy) for his help on AMOVA analyses; and A. Pane (Dipartimento di Gestione dei Sistemi Agroalimentari e Ambientali, Università di Catania, Italy), A. Ippolito (Dipartimento di Biologia e Chimica Agro-forestale e Ambientale, Università di Bari, Italy), and D. E. L. Cooke (James Hutton Institute, Dundee, Scotland, UK) for providing isolates.

\section{LITERATURE CITED}

1. Abbott, C. L., Gilmore, S. R., Lewis, C. T., Chapados, J. T., Peters, R. D., Platt, H. W., Coffey, M. D., and Lévesque, C. A. 2010. Development of a SNP genetic marker system based on variation in microsatellite flanking regions of Phytophthora infestans. Can. J. Plant Pathol. 32:440-457.

2. Álvarez, L. A., Pérez-Sierra, A., Armengol, J., and García-Jiménez, J. 2007. Characterization of Phytophthora nicotianae isolates causing collar and root rot of lavender and rosemary in Spain. J. Plant Pathol. 89:261264.

3. Blair, J. E., Coffey, M. D., Park, S-Y., Geiser, D. M., and Kang, S. 2008. A multi-locus phylogeny for Phytophthora utilizing markers derived from complete genome sequences. Fungal Genet. Biol. 45:266-277.

4. Bonnet, P., Maia, N., Tello-Marquina, J., and Venard, P. 1978. Pouvoir pathogène du Phytophthora parasitica (Dastur): Facteurs de variabilité et notion de spécialisation parasitaire. Ann. Phytopathol. 10:15-29.

5. Brumfield, R. T., Beerli, P., Nickerson, D. A., and Edwards, S. V. 2003. The utility of single nucleotide polymorphisms in inferences of population history. Trends Ecol. Evol. 18:249-256.

6. Cacciola, S. O., and Magnano di San Lio, G. 2008. Management of citrus diseases caused by Phytophthora spp. Pages 61-84 in: Integrated Management of Diseases Caused by Fungi, Phytoplasma and Bacteria. A. Ciancio, and K. G. Mukerji, eds. Springer Science+Business Media B.V., Dordrecht, The Netherlands.

7. Cacciola, S. O., Pane, A., and Magnano di San Lio, G. 1997. Identification and quantitative determination of Phytophthora species infecting ornamental plants in nurseries. Pages 483-485 in: Diagnosis and Identification of Plant Pathogens. H. W. Dehne, G. Adam, M. Diekman, J. Frahm, A. Mauler-Machnik, and P. van Halteren, eds. Kluwer Academic Publishers, Dordrecht, The Netherlands.

8. Cárdenas, M., Grajales, A., Sierra, R., Rojas, A., Gonzalez-Almario, A., Vargas, A., Marin, M., Fermin, G., Lagos, L., Grünwald, N., Bernal, A., Salazar, C., and Restrepo, S. 2011. Genetic diversity of Phytophthora infestans in the Northern Andean region. BMC Genet. 12:23.

9. Chen, Y., and Roxby, R. 1996. Characterization of a Phytophthora infestans gene involved in the vesicle transport. Gene 181:89-94.

10. Clement, M., Posada, D., and Crandall, K. A. 2000. TCS: A computer program to estimate gene genealogies. Mol. Ecol. 9:1657-1660.

11. Colas, V., Lacourt, I., Ricci, P., Vanlerberghe-Masutti, F., Venard, P., Poupet, A., and Panabières, F. 1997. Diversity of virulence in Phytophthora parasitica on tobacco, as reflected by nuclear RFLPs. Phytopathology 88:205-212.

12. Cooke, D. E. L., Schena, L., and Cacciola S. O. 2007. Tools to detect, identify and monitor Phytophthora species in natural ecosystems. J. Plant Pathol. 89:13-28.

13. Dobrowolski, M. P., Tommerup, B. L., Blakeman, H. D., and O'Brien, P. A. 2002. Non-Mendelian inheritance revealed in a genetic analysis of sexual progeny of Phytophthora cinnamomi with microsatellite markers. Fungal Genet. Biol. 35:197-212.

14. Erwin, D. C. 1964. A strain of Phytophthora parasitica from okra and its sexual compatibility with isolates from citrus. Phytopathology 54:114115.

15. Erwin, D. C., and Ribeiro, O. K. 1996. Phytophthora Diseases Worldwide. American Phytopathological Society Press, St. Paul, MN.

16. Excoffier, L., Laval, G., and Schneider, S. 2005. Arlequin ver. 3.0: An integrated software package for population genetics data analysis. Evol. Bioinf. Online 1:47-50.

17. Farris, J. S., Kallersjo, M., Kluge, A. G., and Bult, C. 1995. Testing significance of incongruence. Cladistics 10:315-319.

18. Flot, J. F. 2010. Seqphase: A web tool for interconverting phase input/output files and fasta sequence alignments. Mol. Ecol. Resour. 10:162-166.

19. Gobena, D., McGrath, M. T., and Lamour, K. 2012. Survival and spread of Phytophthora capsici on Long Island, New York. Mycol. Prog. 11:761768.

20. Gobena, D., Roig, J., Galmarini, C., Hulvey, J., and Lamour, K. 2012. Genetic diversity of Phytophthora capsici isolates from pepper and pumpkin in Argentina. Mycologia 104:102-107.

21. Godinho, R., Crespo, E. G., and Ferrand, N. 2008. The limits of mtDNA phylogeography: Complex patterns of population history in a highly 
structured Iberian lizard are only revealed by the use of nuclear markers. Mol. Ecol. 17:4670-4683.

22. Gomez-Alpizar, L., Carbone, I., and Ristaino, J. B. 2007. An Andean origin of Phytophthora infestans inferred from mitochondrial and nuclear gene genealogies. Proc. Natl. Acad. Sci. USA 104:3306-3311.

23. Goodwin, S. B. 1997. The population genetics of Phytophthora. Phytopathology 87:462-473.

24. Goss, E. M., Carbone, I., and Grünwald, N. J. 2009. Ancient isolation and independent evolution of the three clonal lineages of the exotic sudden oak death pathogen Phytophthora ramorum. Mol. Ecol. 18:1161-1174.

25. Goss, E. M., Larsen, M., Vercauteren, A., Werres, S., Heungens, K., and Grünwald, N. J. 2011. Phytophthora ramorum in Canada: Evidence for migration within North America and from Europe. Phytopathology 101:166-171.

26. Grünwald, N. J., and Flier, W. G. 2005. The biology of Phytophthora infestans at its center of origin. Annu. Rev. Phytopathol. 43:171-190.

27. Grünwald, N. J., and Goss, E. M. 2011. Evolution and population genetics of exotic and re-emerging pathogens: novel tools and approaches. Annu. Rev. Phytopathol. 49:249-267.

28. Guindon, S., and Gascuel, O. 2003. A simple, fast and accurate algorithm to estimate large phylogenies by maximum likelihood. Syst. Biol. 52:696704.

29. Hu, J. H., Hong, C. X. Stromberg, E. L., and Moorman, G. W. 2008. Mefenoxam sensitivity and fitness analysis of Phytophthora nicotianae isolates from nurseries in Virginia, USA. Plant Pathol. 57:728-736.

30. Hulvey, J., Gobena, D., Finley, L., and Lamour, K. 2010. Co-occurrence and genotypic distribution of Phytophthora species recovered from watersheds and plant nurseries of eastern Tennessee. Mycologia 102: 1127-1133.

31. Hulvey, J., Hurtado-Gonzalez, O., Aragón-Caballero, L., Gobena, D., Storey, D., Finley, L., and Lamour, K. 2011. Genetic diversity of the pepper pathogen Phytophthora capsici on farms in the Amazonian high jungle of Peru. Am. J. Plant Sci. 2:461-466.

32. Hurtado-Gonzales, O., Aragon-Caballero, L., Apaza-Tapia, W., Donahoo, R., and Lamour, K. 2008. Survival and spread of Phytophthora capsici in Coastal Peru. Phytopathology 98:688-694.

33. Jiang, R. H. Y., Brett, M. T., Whisson, S. C., Hardham, A. R., and Govers, F. 2006. Ancient origin of elicitin gene clusters in Phytophthora genomes. Mol. Biol. Evol. 23:338-351.

34. Johnson, E. S., Wolff, M. F., Wernsman, E. A., Atchely, W. R., and Shew, H. D. 2002. Origin of the black shank resistance gene, $\mathrm{Ph}$, in tobacco cultivar Coker 371-gold. Plant Dis. 86:1080-1084.

35. Kebdani, N., Pieuchot, L., Deleury, E., Panabières, F., Le Berre, J. Y., and Gourgues, M. 2010. Cellular and molecular characterization of Phytophthora parasitica appressorium-mediated penetration. New Phytol. 185: 248-257.

36. Lamour, K. H., Daughtrey, M. L., Benson, D. M., Hwang, J., and Hausbeck, M. K. 2003. Etiology of Phytophthora drechsleri and P. nicotianae (=P. parasitica) diseases affecting floriculture crops. Plant Dis. 87:854-858.

37. Lamour, K. H., Stam, R., Jupe, J., and Huitema, E. 2011. The oomycete broad-host-range pathogen Phytophthora capsici. Mol. Plant Pathol. 13:329-337.

38. Librado, P., and Rozas, J. 2009. DnaSP v5: A software for comprehensive analysis of DNA polymorphism data. Bioinformatics 25:1451-1452.

39. Mammella, M. A., Cacciola, S. O., Martin, F., and Schena, L. 2011. Genetic characterization of Phytophthora nicotianae by the analysis of polymorphic regions of the mitochondrial DNA. Fungal Biol. 115:432442 .

40. Martin, F. 1995. Meiotic instability of Pythium sylvaticum as demonstrated by inheritance of nuclear markers and karyotype analysis. Genetics 139:1233-1246.

41. Martin, F. N. 2008. Mitochondrial haplotype determination in the oomycete plant pathogen Phytophthora ramorum. Curr. Genet. 54:23-34.

42. Martin, F. N., Abad, Z. G., Balci, Y., and Ivors, K. 2012. Identification and detection of Phytophthora: reviewing our progress, identifying our needs. Plant Dis. 96:1080-1103.

43. Martin, F. N., and Coffey, M. D. 2012. Mitochondrial haplotype analysis for differentiation of isolates of Phytophthora cinnamomi. Phytopathology 102:229-239.
44. Martin, F. N., and Tooley, P. W. 2003. Phylogenetic relationships among Phytophthora species inferred from sequence analysis of mitochondrially encoded cytochrome oxidase I and II genes. Mycologia 95:269-284.

45. Matheron, M. E., and Matejka, J. C. 1990. Differential virulence of Phytophthora parasitica recovered from Citrus and other plants to rough lemon and tomato. Plant Dis. 74:138-140.

46. Milne, I., Lindner, D., Bayer, M., Husmeier, D., McGuire, G., Marshall, D. F., and Wright, F. 2009. TOPALi v2: A rich graphical interface for evolutionary analyses of multiple alignments on HPC clusters and multicore desktops. Bioinformatics 25:126-127.

47. Moralejo, E., Pérez-Sierra, A. M., Álvarez, L. A., Belbahri, L., Lefort, F., and Descals, E. 2009. Multiple alien Phytophthora taxa discovered on diseased ornamental plants in Spain. Plant Pathol. 58:100-110.

48. Ospina-Giraldo, M. D., and Jones, R. W., 2003. Characterization of the glucose-6-phosphate isomerase gene in Phytophthora infestans reveals the presence of multiple alleles. Fungal Genet. Biol. 40:197-206.

49. Pane, A., Martini, P., Chimento, A., Rapetti, S., Savona, S., Grasso, F. M., and Cacciola, S. O. 2005. Phytophthora species on ornamental plants in Italy. J. Plant Pathol. S87:301.

50. Parkunan, V., Johnson, C. S., Bowman, B. C., and Hong, C. X. 2010. Population structure, mating type, and mefenoxam sensitivity of Phytophthora nicotianae in Virginia tobacco fields. Plant Dis. 94:1361-1365.

51. Qutob, D., Kamoun, S., and Gijzen, M. 2002. Expression of a Phytophthora sojae necrosis-inducing protein occurs during transition from biotrophy to necrotrophy. Plant J. 32:361-373.

52. Ronquist, F., and Huelsenbeck, J. P. 2003. MrBayes 3: Bayesian phylogenetic inference under mixed models. Bioinformatics 19:1572-1574

53. Schena, L., Cardle, L., and Cooke, D. 2008. Use of genome sequence data in the design and testing of SSR markers for Phytophthora species. BMC Genomics 9:620.

54. Schena, L., and Cooke, D. E. L. 2006. Assessing the potential of regions of the nuclear and mitochondrial genome to develop a "molecular tool box" for the detection and characterization of Phytophthora species. J. Microbiol. Methods 67:70-85.

55. Schlotterer, C. 2000. Evolutionary dynamics of microsatellite DNA. Chromosoma 109:365-371.

56. Schwingle, B. W., Smith, J. A., and Blanchette, R. A. 2007. Phytophthora Species associated with diseased woody ornamentals in Minnesota nurseries. Plant Dis. 91:97-102.

57. Shan, W., and Hardham, A.R. 2004. Construction of a bacterial artificial chromosome library, determination of genome size, and characterization of an Hsp70 gene family in Phytophthora nicotianae. Fungal Genet. Biol. 41:369-380.

58. Stokstad, E. 2004. Nurseries may have shipped sudden oak death pathogen nationwide. Science 303:1959.

59. Sullivan, M. J., Parks, E. J., Cubeta, M. A., Gallup, C.A., Melton, T. A., Moyer, J. W., and Shew, H. D. 2010. An assessment of the genetic diversity in a field population of Phytophthora nicotianae with a changing race structure. Plant Dis. 94:455-460.

60. Van der Lee, T., Testa, A., Robold, A., van 't Klooster, J., and Govers, F 2004. High-density genetic linkage maps of Phytophthora infestans reveal trisomic progeny and chromosomal rearrangements. Genetics 167:16431661.

61. Vercauteren, A., Boutet, X., D’hondt, L., Van Bockstaele, E., Maes, M., Leus, L., Chandelier, A., and Heungens, K. 2011. Aberrant genome size and instability of Phytophthora ramorum oospore progenies. Fungal Genet. Biol. 48:537-543.

62. Wright, S. 1965. The interpretation of population structure by F-statistics with special regard to systems of mating. Evolution 19:395-420.

63. Yakabe, L. E., Blomquist, C. L., Thomas, S. L., and MacDonald, J. D. 2009. Identification and frequency of Phytophthora species associated with foliar diseases in California ornamental nurseries. Plant Dis. 93:884890.

64. Zhang, D. X., and Hewitt, G. M. 2003. Nuclear DNA analyses in genetic studies of populations: Practice problems and prospects. Mol. Ecol. 12:563-584.

65. Zhang, X. G., Sun, W. X., Guo, L., Yu, J. F., and Chang, C. J. 2003. Genetic and pathogenic variation among tobacco black shank strains of Phytophthora parasitica var. nicotianae from the main tobacco growing in China. J. Phytopathol. 151:259-266. 